\title{
Effect of circadian system disruption on the concentration and daily oscillations of cortisol, progesterone, melatonin, serotonin, growth hormone, and core body temperature in periparturient dairy cattle
}

\author{
Aridany Suarez-Trujillo, ${ }^{1} \odot$ Nguyen Hoang, ${ }^{2}$ Leela Robinson, ${ }^{1}$ Conor J. McCabe,,${ }^{1}$ Dawn Conklin, ${ }^{3} \oplus$ \\ Radiah C. Minor, ${ }^{3} \odot$ Jonathan Townsend, ${ }^{4} \odot$ Karen Plaut, ${ }^{1} \odot$ Uduak Z. George, ${ }^{2} \odot$ Jacquelyn Boerman, ${ }^{1} \odot$ \\ and Theresa M. Casey ${ }^{1 *}$ (ㅇ) \\ ${ }^{1}$ Department of Animal Sciences, Purdue University, West Lafayette, IN 47907 \\ ${ }^{2}$ Department of Mathematics and Statistics, San Diego State University, San Diego, CA 92182 \\ ${ }^{3}$ Department of Animal Sciences, North Carolina Agricultural and Technical State University, Greensboro 27401 \\ ${ }^{4}$ Department of Veterinary Clinical Sciences, Purdue University, West Lafayette, IN 47907
}

\begin{abstract}
Metabolic, circadian, sleep, and reproductive systems are integrated and reciprocally regulated, but the understanding of the mechanism is limited. To study this integrated regulation, the circadian timing system was disrupted by exposing late pregnant nonlactating (dry) cows to chronic shifts in the light-dark phase, and rhythms of body temperature and circulating cortisol (CORT), progesterone (P4), serotonin (5HT), melatonin (MEL), and growth hormone $(\mathrm{GH})$ concentrations were measured. Specifically, across 2 identical studies (1 and 2), at $35 \mathrm{~d}$ before expected calving (BEC) multiparous cows were assigned to control $(\mathrm{CON} ; \mathrm{n}=24)$ and exposed to $16 \mathrm{~h}$ light and $8 \mathrm{~h}$ dark or phase shift $(\mathrm{PS} ; \mathrm{n}=24)$ treatments and exposed to 6 -h light-dark phase shifts every $3 \mathrm{~d}$ until parturition. All cows were exposed to control lighting after calving. Blood samples were collected in the first study at $0600 \mathrm{~h}$ on $\mathrm{d} 35$ BEC, d 21 BEC, and $2 \mathrm{~d}$ before calving, and d 0, 2, 9, 15, and 22 postpartum (PP). A subset of cows (n $=6 /$ group) in study 1 was blood sampled every $4 \mathrm{~h}$ over $48 \mathrm{~h}$ beginning on d $23 \mathrm{BEC}, 9 \mathrm{BEC}$, and $5 \mathrm{PP}$. Body temperature was measured every $30 \mathrm{~min}(\mathrm{n}=$ 8-16/treatment) for $48 \mathrm{~h}$ at $23 \mathrm{BEC}$ and $9 \mathrm{BEC}$ in both studies; and at $14 \mathrm{PP}$ and $60 \mathrm{PP}$ only in study 2. Treatment did not affect levels of CORT, GH, or $\mathrm{P} 4$ at $0600 \mathrm{~h}$, but overall level of $5 \mathrm{HT}$ was lower and MEL higher in PS cows across days sampled. A 2-component versus single-component cosinor model better described [ $>$ coefficient of determination $\left(\mathrm{R}^{2}\right)$; $<$ Akaike information criterion and $<$ Bayesian information criterion] daily oscillations of all hormones and tempera-
\end{abstract}

Received May 2, 2021.

Accepted November 1, 2021.

*Corresponding author: Theresa-casey@purdue.edu ture for both treatments. Circadian rhythm fit $\left(\mathrm{R}^{2}\right)$ of body temperature and MEL increased from 23 BEC to $9 \mathrm{BEC}$ in $\mathrm{CON}$ and was marked by loss of feeding time influence on oscillations in both treatments. Both treatments exhibited circadian rhythms of CORT at 9 BEC, CON cows also exhibited circadian rhythms in $\mathrm{P} 4$ at $23 \mathrm{BEC}$, and 5HT at 9 BEC. Daily oscillations in temperature and hormones, except CORT, were affected by PS treatment in the prepartum and were associated with longer gestation. In the PP, circadian rhythmicity was lost or diminished for all hormones and body temperature in both treatments. Stronger rhythms of body temperature and multiple hormones at 1 wk prepartum may indicate a synchronizing cue to time parturition. Therefore, dairy systems may need to consider management factors that affect circadian clocks in late-gestation cows.

Key words: growth hormone, cortisol, progesterone, melatonin, serotonin

\section{INTRODUCTION}

A successful transition through the 45- to 60-d nonlactating (dry) preparturition period, calving, and commencement of lactation is a strong predictor of the health and performance success of dairy cattle during the whole lactation (Duffield, 2007; Duffield et al., 2009). A critical element to cow health and welfare is remaining in metabolic balance (maintaining homeostasis) during this time. Animals have evolved multiple homeostatic regulators; among them is the circadian timing system, which generates 24-h rhythms of physiology and behavior to synchronize internal physiology to the external environment. The circadian timing system also plays an important role in regulating homeorhetic adaptations, which are coordinated metabolic changes to support dominant physiological processes such as growth, pregnancy, and lactation (Hanon et 
al., 2008; Bauman, 2010; Casey et al., 2016). Circadian clocks and the rhythms they generate are affected by reproductive status, with daily rhythms being modified in females throughout estrous cycles, pregnancy, and lactation. Changes in daily rhythms are due in part to hormonal environments of reproductive states (Olcese, 2014; Pinto-Santini and Ungerfeld, 2019; Casey et al., 2020). In addition to changes in metabolism and circadian rhythms across reproductive states, the sleep-wake activity is also altered in cattle (Ternman et al., 2019) and other mammalian species (Skouteris et al., 2009; Wilson et al., 2013; Reid et al., 2017). It is clear that metabolic, circadian, sleep, and reproductive systems are integrated and reciprocally regulated, but the understanding of how, particularly during late pregnancy and early lactation, is limited (Kuljis et al., 2013).

Integration and reciprocal regulation of physiological systems occurs through feedback loops that exist at the cellular and supracellular level, and result in the establishment of periodic oscillations in physiology and behavior (Goldbeter, 2008; Goldbeter et al., 2012). Among the daily oscillations resulting from the integrated feedback loops are the circulating levels of hormones and core body temperature. To better understand the role of the circadian timing system in regulation of metabolic and hormonal adaptations during late pregnancy and the onset of lactation in dairy cattle, we conducted a study that disrupted the functioning of the circadian timing system beginning at $5 \mathrm{wk}$ before expected calving (BEC) in nonlactating, dry cows. Factors that act to entrain the time of clocks are also capable of disrupting clocks when applied at unusual and inappropriate times. Under natural conditions, circadian rhythms are synchronized to the regular 24-h light-dark cycles that are generated by the rotation of the earth. Alterations of natural light-dark cycles disrupt circadian clocks (Papagiannakopoulos et al., 2016; Skinner et al., 2019). A chronic jet-lag model developed to study the effect of environmental disruption of circadian clocks on rodent behavior and physiology (Reddy et al., 2002; Davidson et al., 2009) was used in our studies. In particular, to disrupt circadian clocks, cows were exposed to chronic light-dark phase shifts (PS) every $3 \mathrm{~d}$. The objectives of studies described were (1) to describe the daily patterns of body temperature and reproductive and metabolic hormones [total cortisol (CORT), progesterone (P4), serotonin (5HT), melatonin (MEL), and growth hormone $(\mathbf{G H})$ ] in late pregnant and early lactation dairy cattle; and (2) to determine the effect of circadian disruption on these oscillations. We hypothesized that the circadian timing system influences the daily oscillations in hormones and body temperature in late pregnant dairy cattle, and thus exposure to chronic light-dark
PS would affect rhythms of temperature and metabolic and reproductive hormones.

\section{MATERIALS AND METHODS}

\section{Study Design and Animal Experimental Conditions}

Data for this study were collected as part of 2 larger experiments for which details were previously given (Suarez-Trujillo et al., 2020; McCabe et al., 2021b), but are described here in brief. Before beginning the study at the Dairy Unit of the Purdue Animal Sciences Research and Education Center, the protocol was reviewed and approved by the Purdue University Institutional Animal Care and Use Committee. The SuarezTrujillo et al. (2020) (study 1) study was performed between January and May 2018, and McCabe et al. (2021b) (study 2) was performed between February and June 2019. In both studies, multiparous Holstein cows ( $\mathrm{n}=32$, study $1 ; \mathrm{n}=16$, study 2$)$ were dried off $60 \mathrm{~d}$ BEC. At 35 d BEC cows were moved to a tie-stall facility and half the cattle in each treatment were assigned to control $(\mathbf{C O N}, \mathrm{n}=24)$ or PS $(\mathrm{n}=24)$ treatment by matching for parity $(2.85 \pm 1.04)$, previous lactation milk yield, and previous lactation metabolic and mammary-related disease history. Mean BW of CON $(755 \pm 18.66 \mathrm{~kg})$ and PS $(757 \pm 18.62 \mathrm{~kg})$ and mean BCS (1-5 scale) of CON cows $(3.53 \pm 0.06)$ and PS $(3.42 \pm 0.06)$ were not different at $35 \mathrm{~d}$ BEC in both studies. Blood sample collection for analysis of circulating hormone levels was performed in study 1 cattle (n =32) described by Suarez-Trujillo et al. (2020). Body temperature was recorded in study 1 and 2 cattle for the 2 prepartum time points ( $23 \mathrm{~d}$ BEC and $9 \mathrm{~d}$ BEC), and study 2 alone for the postpartum (PP) time points $(14 \mathrm{~d}$ PP and $60 \mathrm{~d} \mathrm{PP})$. Some cows used in study $1(\mathrm{n}=$ 7) were also enrolled in study 2 , and they were assigned to opposite treatments in the second trial.

In both studies, treatment areas in the experimental tie-stall barn were divided by double-draping of fireretardant tarps (Tarps Plus, Abadak Inc.) from floor to ceiling to create a light-proof partition. To eliminate natural light, windows were covered with light-resistant black plastic and caulking was added around doors. On the CON treatment side, cows were exposed to $16 \mathrm{~h}$ of light and $8 \mathrm{~h}$ of dark, with lights turned on at $0430 \mathrm{~h}$ and off at $2030 \mathrm{~h}$. On the PS treatment side, cows were exposed to $16 \mathrm{~h}$ light and $8 \mathrm{~h}$ dark, but the light phase was shifted forward $6 \mathrm{~h}$ every $3 \mathrm{~d}$. Bright white LED lights (Smart Electrician $5000 \mathrm{~lm} 46 \times 6$ LED Tread Plate Shop Light; Menards Inc.) were positioned to provide $150 \mathrm{~lx}$ at eye level of animals. The PS cows were exposed to $\geq 10$ light shifts during the treatment period 
(35 d BEC to $3 \mathrm{~d}$ BEC). Ambient temperature in the experimental barn varied no more than $5^{\circ} \mathrm{C}\left(10-15^{\circ} \mathrm{C}\right)$ from the start of the study (mid January) to the end (late May) and was the same on both treatment sides. Cows were exercised twice daily (0430 and $1530 \mathrm{~h}$ ) for $30 \mathrm{~min}$ by releasing them into a gated holding pen. At approximately $3 \mathrm{~d}$ BEC, animals were moved to the maternity barn. Beginning at this point, all animals were exposed to CON light-dark phase schedule for the remainder of the study. In the maternity barn cows were housed in box-stalls for calving until $3 \mathrm{~d}$ after parturition. If cows showed signs of parturition before $\mathrm{d}$ 3 BEC, they were moved to the maternity barn immediately. All cows were moved back to the tie-stall barn from 3 to 15 DIM, and then were moved to a free-stall barn for the remainder of the studies.

Cows were fed once daily at $1600 \mathrm{~h}$ preparturition, and at $1100 \mathrm{~h}$ postparturition in study 1 and at $1600 \mathrm{~h}$ in both periods in study 2 . In both studies, cattle were fed for ad libitum intake by feeding $110 \%$ of intake from the previous day. Individual intake was determined from $35 \mathrm{~d}$ BEC to 15 postparturition by measuring feed offered and refused from the previous day. Preparturition, cows were fed a prefresh ration $(57.0 \%$ DM, $33.2 \%$ NDF, $15.8 \% \mathrm{CP}, 39.6 \% \mathrm{NFC}$, and $3.9 \%$ fatty acids) and after parturition they were fed a lactation ration (49.9\% DM, 28.6\% NDF, $15.6 \%$ CP, $42.2 \%$ NFC, and $5.4 \%$ fatty acids); for details of diets, see Suarez-Trujillo et al. (2020).

\section{Plasma Hormone and Core Body Temperature Analysis}

To capture how circulating hormones changed from late pregnancy to lactation and to determine whether this affected phase-shift treatment, a single blood sample was taken from the coccygeal vein between 0530 and $0600 \mathrm{~h}$ on d 35, 21, 7, 6, 5, 4, 3, 2, and 1 , before parturition and 2, 5, 9, 15, and $22 \mathrm{~d}$ PP. The only samples used for hormone concentration determination from the period $7 \mathrm{~d}$ BEC to parturition were the samples representing the actual $\mathrm{d} 2$ before calving (BC) for each cow and the samples collected on the day of calving.

To capture circadian oscillations in circulating levels of hormones, a subset of cows $(\mathrm{CON}, \mathrm{n}=6$; PS, $\mathrm{n}=$ 6 ) was blood sampled every $4 \mathrm{~h}$ over a 48 -h period. Because not all the cows were enrolled at the same time, this subset of cows was the first 6 cows enrolled in each treatment for study 1 . Cows were catheterized $24 \mathrm{~h}$ before sampling, and indwelling jugular catheters were inserted without anesthesia. Circadian blood sampling began at $0600 \mathrm{~h}$ on 23 and $9 \mathrm{~d}$ BEC and $5 \mathrm{~d}$ PP.
All blood samples were transferred into EDTA tubes (Becton Dickinson) and centrifuged at $4^{\circ} \mathrm{C}$ for $15 \mathrm{~min}$ at $2,000 \times g$ immediately following collection. Plasma was transferred to microfuge tubes and stored at $-20^{\circ} \mathrm{C}$ until analysis.

Plasma MEL, 5HT, CORT, and P4 concentrations were measured with liquid chromatography-tandem MS. Melatonin and 5HT were measured in the same liquid chromatography-tandem MS analysis. To measure MEL and $5 \mathrm{HT}, 500 \mu \mathrm{L}$ of plasma was spiked with $25 \mathrm{ng}$ of melatonin-d4 (M215002, Toronto Research Chemicals) and $50 \mathrm{ng}$ of 5HT-d4 (Cayman Chemical). Acetonitrile (1:4 vol/vol) was added, vortexed, and samples centrifuged at $3,220 \times g$ for $10 \mathrm{~min}$ at room temperature. Supernatant was vacuum dried and stored at $-80^{\circ} \mathrm{C}$ until analysis. Chromatography was performed using an Imtakt Intrada Amino Acid $3 \mu \mathrm{m}$ $2 \times 150 \mathrm{~mm}$ column (Chrom Tech Inc.) as described by Zhao et al. (2016). Standard curve $\left(\mathrm{R}^{2}=0.99\right)$ in combination with internal standard was used to calculate concentrations. The coefficient of variation of extraction efficiency was calculated by comparing the peak area of deuterated standard spiked in each sample for both molecules (MEL: 14.7\%; 5HT: 11.1\%). The coefficients of variation of retention time of peaks were $0.53 \%$ for MEL and $0.54 \%$ for 5HT (Zhang et al., 2020).

Total CORT and P4 were determined in $400 \mu \mathrm{L}$ of plasma sample, spiked with 10 ng of cortisol-d (C696302, Toronto Research Chemicals) and $10 \mathrm{ng}$ of progesterone-d (P755902, Toronto Research Chemicals). Samples were extracted by adding $2 \mathrm{~mL}$ of acetoacetate/hexane $(1: 1)$ and vortexed for $10 \mathrm{~min}$. Samples were centrifuged at $3,220 \times g$ for $10 \mathrm{~min}$ at room temperature. The upper organic phase was transferred to a new tube, vacuum dried, and stored at $-80^{\circ} \mathrm{C}$ until analysis. The CORT and P4 chromatography were performed using a

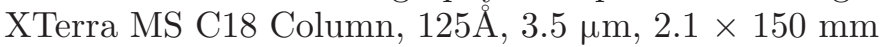
(Waters Corp.). Concentration was calculated based on the internal standard spiked in each sample. The coefficient of variation of extraction efficiency was $12.6 \%$ for CORT and $10.2 \%$ for $\mathrm{P} 4$. The coefficients of variation of retention time of peaks were $0.18 \%$ for CORT and $0.26 \%$ for P4.

Growth hormone was measured with a commercial ELISA (intraassay CV $=7.6 \%$, interassay $\mathrm{CV}=2.0 \%$; MBS703041, MyBiosource) following the manufacturer's instructions.

\section{Circadian Rhythm Assessment}

Vaginal temperature was recorded every 30 min over a 48-h period at 23 and $9 \mathrm{~d}$ BEC and 14 and $60 \mathrm{~d}$ PP using internal temperature loggers (iButton DS1921H- 
F5\#, iButtonLink Technology) secured to a blank controlled internal drug release device (EAZI-Breed CIDR Cattle Insert, Zoetis Inc.) and inserted into the vagina.

\section{Data and Statistical Analysis}

Data of hormone concentration measured throughout the transition period was analyzed using the PROC MIXED in SAS 9.4 (SAS Institute Inc.). An autoregressive $[\operatorname{AR}(1)]$ covariance structure was selected based on minimizing Akaike information criterion (AIC) and Bayesian information criterion (BIC). The model included the fixed effects of time point, treatment, and their interaction, and the random effect of cow nested within treatment.

$$
Y_{i j k}=\mu+T_{i}+D_{j}+\left(T_{i} \times D_{j}\right)+C(T)_{i k}+e_{i j k}
$$

where $Y_{i j k}=$ dependent variable, $\mu=$ overall mean, $T_{i}$ $=$ the fixed effect of treatment $(i=\mathrm{CON}$ or PS $), D_{j}$ $=$ the fixed effect of day $[j=\mathrm{d} 35,21$, and 2, before parturition and 2, 5, 9, 15, and $22 \mathrm{~d}$ after parturition $(\mathrm{PP})], T_{i} \times D_{j}=$ interaction between treatment and day, $C(T)_{i k}=$ random effect of cow nested within treatment, and $e_{i j k}=$ random error. Data were expressed as least squares means and standard error of means; $P \leq$ 0.05 was considered significant.

Fitting to cosinor models was performed with data collected from analysis of 4-h sampling over the three 48-h periods of hormone concentration and core body temperature using RStudio (v.1.1.453). Two analyses were performed, single-component cosinor and a 2-component cosinor, and models were compared to determine which model better fit data. The single-component cosinor has one cosine function (Madden et al., 2018). The equation for the single-component cosinor model for circadian rhythms is as follows (Cornelissen, 2014):

$$
y_{i}=M+A \cos \left(\frac{2 \pi t_{i}}{24}+\phi\right)+\varepsilon\left(t_{i}\right)
$$

where $y_{i}$ is the value of the measured variable at time $t_{i}$; $M$ is a rhythm-adjusted mean known as the midline estimating statistic of rhythms (mesor) of $y_{i}$ throughout a complete cycle; $A$ is the amplitude of the curve on either side of $M$ (i.e., half the difference between the highest and the lowest calculated values); $\phi$ is the acrophase (a measure of the time of overall high values recurring in each cycle), and $\varepsilon\left(t_{i}\right)$ is the error (Bingham et al., 1982; Refinetti et al., 2007; Fernández et al., 2009; Cornelissen, 2014). The period (duration of 1 cycle) is $24 \mathrm{~h}$. The single-component cosinor can be rewritten as a linear combination of sine and cosine functions:

$$
y_{i}=M+\gamma_{1} \cos \left(\frac{2 \pi t_{i}}{24}\right)+\gamma_{2} \sin \left(\frac{2 \pi t_{i}}{24}\right)+\varepsilon\left(t_{i}\right)
$$

where $\gamma_{1}=A \cos (\phi)$ and $\gamma_{2}=-A \sin (\phi)$ are coefficients used to calculate $A$ and $\phi$ (Moškon, 2020):

$$
\phi= \begin{cases}A=\sqrt{\gamma_{1}^{2}+\gamma_{2}^{2}}, \\ -\arctan \left(\left|\frac{\gamma_{2}}{\gamma_{1}}\right|\right) & \gamma_{1}>0, \gamma_{2}>0, \\ \left.-\pi+\arctan \left(\mid \frac{\gamma_{2}}{\gamma_{1}}\right)\right) & \gamma_{1}<0, \gamma_{2}>0, \\ \left.-2 \pi+\arctan \left(\mid \frac{\gamma_{2}}{\gamma_{1}}\right)\right) & \gamma_{1}>0, \gamma_{2}<0, \\ -\pi-\arctan \left(\left|\frac{\gamma_{2}}{\gamma_{1}}\right|\right) & \gamma_{1}<0, \gamma_{2}<0 .\end{cases}
$$

The single-component cosinor can be extended to a 2-component model consisting of cosine curves with periods of 24 and $12 \mathrm{~h}$ (Cornelissen, 2014). A 2-or-more component model is useful when approximating a waveform that is not sinusoidal. It can describe waveforms with complex oscillatory dynamics that cannot be approximated with a single-component cosinor (Moškon, 2020). The 2-component cosinor is (Cornelissen, 2014) as follows:

$$
y_{i}=M+\sum_{i=1}^{2} A_{i} \cos \left(\frac{2 i \pi t_{i}}{24}+\phi_{i}\right)+\varepsilon\left(t_{i}\right) .
$$

We can rewrite the 2-component cosinor model as a linear combination of sine and cosine functions and obtain:

$$
\begin{aligned}
& y_{i}=M+\gamma_{1} \cos \left(\frac{2 \pi t_{i}}{24}\right)+\gamma_{2} \sin \left(\frac{2 \pi t_{i}}{24}\right)+\gamma_{3} \cos \left(\frac{4 \pi t_{i}}{24}\right) \\
& +\gamma_{4} \sin \left(\frac{4 \pi t_{i}}{24}\right)+\varepsilon\left(t_{i}\right),
\end{aligned}
$$

where $\gamma_{3}=A_{2} \cos \left(\phi_{2}\right)$ and $\gamma_{4}=-A_{2} \sin \left(\phi_{2}\right)$, and the amplitude $A_{2}$ is

$$
A_{2}=\sqrt{\gamma_{3}^{2}+\gamma_{4}^{2}}
$$

Models were visually compared, and the coefficient of determination $\left(\mathrm{R}^{2}\right)$ was then compared, as this captures 
the true variation across animals and the statistical significance of treatment.

After calculation of mesor $(M)$, amplitude $(A)$, acrophase $(\phi)$, and $\mathrm{R}^{2}$ for each cow by treatment (CON and PS) and time point (23 d BEC, $9 \mathrm{~d}$ BEC, and $5 \mathrm{~d}$ $\mathrm{PP}$ ) for hormone concentration over 48 -h periods, data were analyzed using the PROC MIXED in SAS with treatment, time point, and interaction between treatment and time point as fixed effects, and cow within treatment as random effect. Similarly, comparison of mesor $(M)$, amplitude $(A)$, acrophase $(\phi)$, and $\mathrm{R}^{2}$, calculated for each cow by treatment (CON and PS) and time point (23 d BEC, $9 \mathrm{~d}$ BEC, $14 \mathrm{~d}$ PP, and $60 \mathrm{~d}$ $\mathrm{PP})$ for core body temperature was performed using PROC MIXED in SAS with treatment, time point, and interaction between treatment and time point as fixed effects, and cow within treatment and study as random effects.

Finally, the sum of squares error (SSE), AIC, and BIC were calculated to evaluate which model (single versus 2-component cosinor) is preferred within parameters measured (body temperature and hormones). The model with the lowest AIC and BIC was preferred and were calculated using the following formulas:

$$
\begin{aligned}
& \mathrm{AIC}=2 k+n\left[\ln \left(\frac{2 \pi \mathrm{SSE}}{n}\right)+1\right], \\
& \mathrm{BIC}=k \ln (n)+n \ln \left(\frac{\mathrm{SSE}}{n}\right),
\end{aligned}
$$

where $n$ is the number of data points, $k$ is the number of parameters in the model, and SSE calculated as

$$
\mathrm{SSE}=\sum_{i=1}^{n}\left(y_{i}-\bar{y}\right)^{2}
$$

is the sum of the squared differences between each prediction $y_{i}$ and the mean of the group data.

\section{RESULTS}

\section{Effect of Treatment on Calving Date}

In the first study (Suarez-Trujillo et al., 2020), CON cows tended to calve on average $3.75 \mathrm{~d}(3.75 \pm 3.79 \mathrm{~d}$; mean \pm SD) before expected due date, and PS cows calved at $1.6 \mathrm{~d}(1.60 \pm 3.58 \mathrm{~d})$ before the due date $(P$ $=0.08)$. In the second study (McCabe et al., 2021b), CON cows calved $4.25 \pm 2.66 \mathrm{~d}$ before expected due date and PS cows calved $3.25 \pm 2.55 \mathrm{~d}$ before expected due date $(P=0.45)$. Analysis across both studies found that gestation length was significantly longer $(P=$
$0.05)$ for the PS-treated $(2.00 \pm 3.34 \mathrm{~d}$ before expected due date) versus CON (3.92 $\pm 3.40 \mathrm{~d}$ before expected due date) cows.

\section{Changes in Daily Oscillations of Core Body Temperature Across the Transition Period and the Effect of PS Treatment}

Two analyses were run to determine how well single or 2-component cosinor fit the data. The first analysis tested the fit of the single or 2-component cosinor models to the mean data across all cows within a treatment and time point, and goodness of fit was evaluated by comparing resulting graphs and coefficient of regression $\left(\mathrm{R}^{2}\right)$. The second analysis tested the fit of each model to individual cow data and then mixed-model analysis was used to compare effect of treatment, time point, and treatment by time point.

Analysis of mean core body temperature across CON cows indicated that fit of data to a 2-component cosinor model $\left(\mathrm{R}^{2}=0.72\right)$ was stronger than a single-component $\left(\mathrm{R}^{2}=0.49\right)$ at $23 \mathrm{BEC}$ (Figure $\left.1 \mathrm{~A}\right)$. Fit of mean core body temperature data of CON at 9 BEC was similar between single $\left(\mathrm{R}^{2}=0.82\right)$ and 2-component $\left(\mathrm{R}^{2}=0.85\right)$ cosinor model and was increased relative to 23 BEC (Figure 1B). At $23 \mathrm{BEC}$ in CON cows, there was a saddling of the curve in the 2-component cosinor model at approximately $1600 \mathrm{~h}$, which was coincident with feeding time. The saddling of the 2-component cosinor curve of CON cows was not present at 9 BEC. The fit of mean core body temperature data across PS cows to 2-component cosinor models $\left(\mathrm{R}^{2}=0.65\right.$ and $\left.\mathrm{R}^{2}=0.60\right)$ was better than the single-component cosinor model $\left(\mathrm{R}^{2}=0.49\right.$ and $\left.\mathrm{R}^{2}=0.51\right)$, but fit of data to either model was relatively unchanged between $23 \mathrm{~d}$ BEC and $9 \mathrm{~d}$ BEC, respectively (Figure $1 \mathrm{E}$ and Figure $1 \mathrm{~F}$ ). Fit of mean core body temperature data to single- and 2-component cosinor curves was similar at both PP time points, for both treatments, and less strong in the $\mathrm{PP}$ than prepartum time points (Figure $1 \mathrm{C}, \mathrm{D}, \mathrm{G}$, and $\mathrm{H}$ ). Adding a third harmonic (i.e., a 3-component cosinor) did not improve the fit (data not shown) of mean core body temperature for either of the treatments or any of the time points. The AIC and BIC parameters were reduced for 2-component cosinor for body temperature in both treatments and all time points, and thus the 2-component cosinor model was preferred (Supplemental Table S1; https://doi.org/10 .4231/KEHG-RN90; Casey et al., 2021a).

Using mean values across animals to determine fit of data to cosinor models may represent a more idealized model or exaggerate the true fit of data. To account for this potential, the fit of individual animal temperature data to the single- and 2-component cosinor models 
A

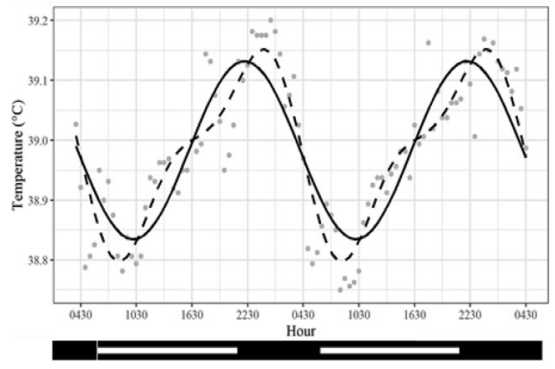

B

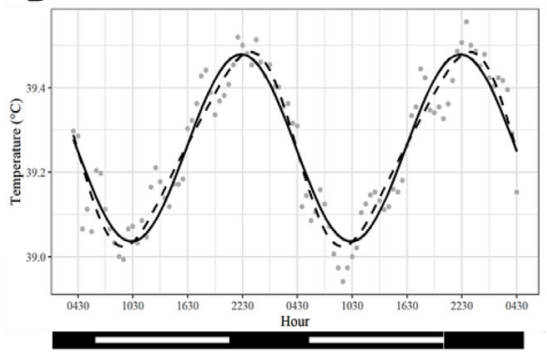

c

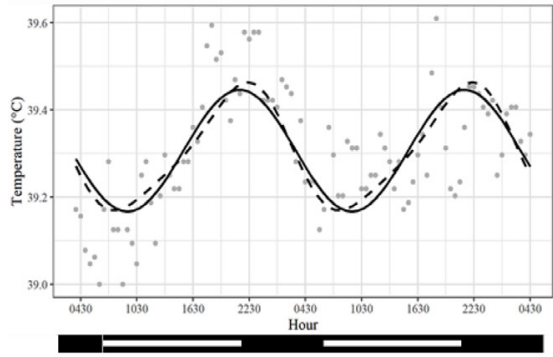

D

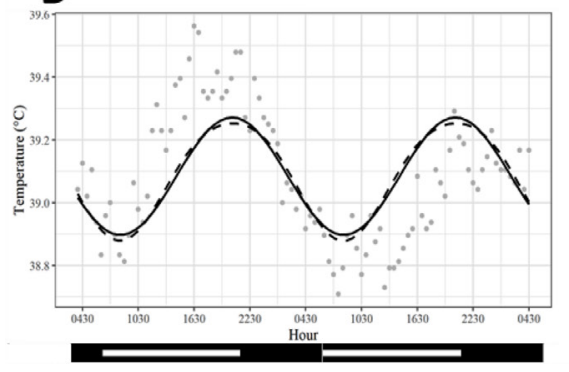

E

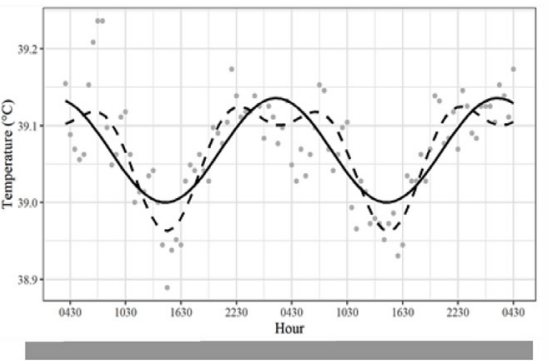

$\mathbf{F}$

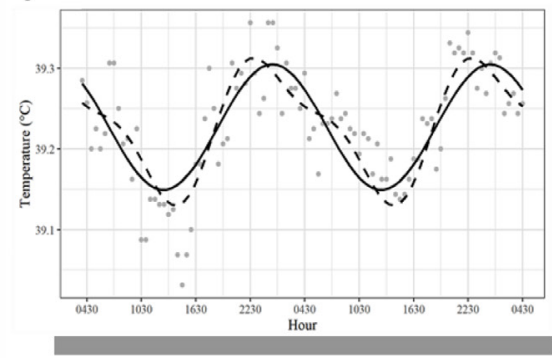

G

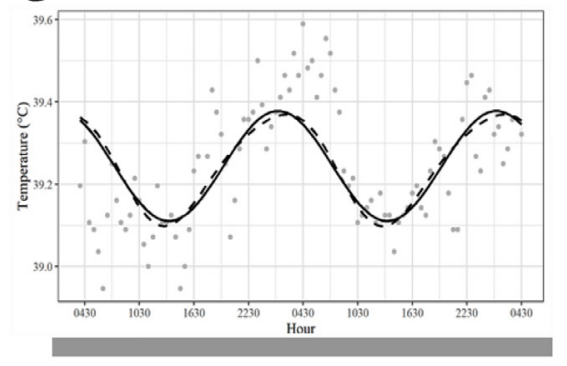

H

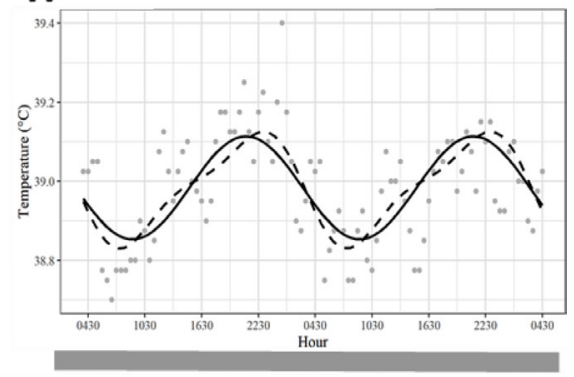

Figure 1. Core body temperature in dairy cows at 23 and $9 \mathrm{~d}$ before expected calving (BEC) and 14 and $60 \mathrm{~d}$ postparturition (PP). Five weeks before calving, cows were exposed to control treatment (CON; $16 \mathrm{~h}$ of light and $8 \mathrm{~h}$ of dark) or phase-shifted treatment (PS; $16 \mathrm{~h}$ of light and $8 \mathrm{~h}$ dark, with the photophase shifted $6 \mathrm{~h}$ every $3 \mathrm{~d}$ ). Body temperature was measured using a temperature logger (iButton, iButtonLink Technology) mounted in an intravaginal device. Temperature started at $0400 \mathrm{~h}$ on $23 \mathrm{~d}$ BEC (A, CON cows, $\mathrm{n}=20 ; \mathrm{E}, \mathrm{PS}$ cows, $\mathrm{n}=17), 9 \mathrm{~d}$ BEC (B, CON cows, $\mathrm{n}=19 ; \mathrm{F}, \mathrm{PS}$ cows, $\mathrm{n}=19), 14 \mathrm{~d} \mathrm{PP}(\mathrm{C}, \mathrm{CON}$ cows, $\mathrm{n}=8$; $\mathrm{G}, \mathrm{PS}$ cows, $\mathrm{n}=7$ ), and $60 \mathrm{~d} \mathrm{PP}(\mathrm{D}, \mathrm{CON}$ cows, $\mathrm{n}=6$; $\mathrm{H}$, PS cows, $\mathrm{n}=5$ ) and recorded temperature every $30 \mathrm{~min}$ over a 48-h period. Gray dots represent the average of the observed data, solid black lines represent the single-component cosinor fitted curve and dashed black lines represent the 2-component cosinor fitted curve. Bars under graph A, B, C, and D represent the light (white) and dark (black) phases. Gray bars under graph E, F, G, and H represent the shifted photoperiod for phase-shifted cows. (A) CON cows at 23 d BEC, $\mathrm{R}^{2}$ single-component cosinor model: 0.71; $\mathrm{R}^{2}$ 2-component cosinor model: 0.81; midline estimating statistic of rhythms (mesor): $38.98^{\circ} \mathrm{C}$; amplitude: $0.15^{\circ} \mathrm{C}$; acrophase: $7.84 \mathrm{~h}$; (B) CON cows at $9 \mathrm{~d}$ BEC, $\mathrm{R}^{2}$ single-component cosinor model: 0.88; $\mathrm{R}^{2}$ 2-component cosinor model: 0.90; mesor: $39.26^{\circ} \mathrm{C}$; amplitude: $0.22^{\circ} \mathrm{C}$; acrophase: $6.16 \mathrm{~h} ;(\mathrm{C}) \mathrm{CON}$ cows at $14 \mathrm{~d} \mathrm{PP}, \mathrm{R}^{2}$ single-component cosinor model: 0.49; $\mathrm{R}^{2}$ 2-component cosinor model: 0.51 ; mesor: $39.31^{\circ} \mathrm{C}$; amplitude: $0.14^{\circ} \mathrm{C}$; acrophase: $7.00 \mathrm{~h}$; (D) $\mathrm{CON}$ cows at $60 \mathrm{~d}$ PP, $\mathrm{R}^{2}$ single-component cosinor model: 0.42 ; $\mathrm{R}^{2}$ 2-component cosinor model: 0.43 ; mesor: $39.08^{\circ} \mathrm{C}$; amplitude: $0.19^{\circ} \mathrm{C}$; acrophase: $7.92 \mathrm{~h}$; $(\mathrm{E}) \mathrm{PS}$ cows at $23 \mathrm{~d}$ BEC, $\mathrm{R}^{2}$ single-component cosinor model: $0.51 ; \mathrm{R}^{2}$ 2-component cosinor model: 0.66 ; mesor: $39.07^{\circ} \mathrm{C}$; amplitude: $0.07^{\circ} \mathrm{C}$; acrophase: 1.69 h; (F) PS cows at 9 d BEC, $\mathrm{R}^{2}$ single-component cosinor model: $0.61 ; \mathrm{R}^{2} 2$-component cosinor model: 0.69 ; mesor: $39.23^{\circ} \mathrm{C}$; amplitude: $0.08^{\circ} \mathrm{C}$; acrophase: $3.53 \mathrm{~h}$; (G) PS cows at $14 \mathrm{~d}$ PP, $\mathrm{R}^{2}$ single-component cosinor model: 0.40; $\mathrm{R}^{2}$ 2-component cosinor model: 0.41; mesor: $39.24^{\circ} \mathrm{C}$; amplitude: $0.13^{\circ} \mathrm{C}$; acrophase: $2.76 \mathrm{~h}$; and (H) PS cows at $60 \mathrm{~d} \mathrm{PP}, \mathrm{R}^{2}$ single-component cosinor model: 0.45 ; $\mathrm{R}^{2}$ 2-component cosinor model: 0.49 ; mesor: $38.98^{\circ} \mathrm{C}$; amplitude: $0.13^{\circ} \mathrm{C}$; acrophase: $7.31 \mathrm{~h}$. 


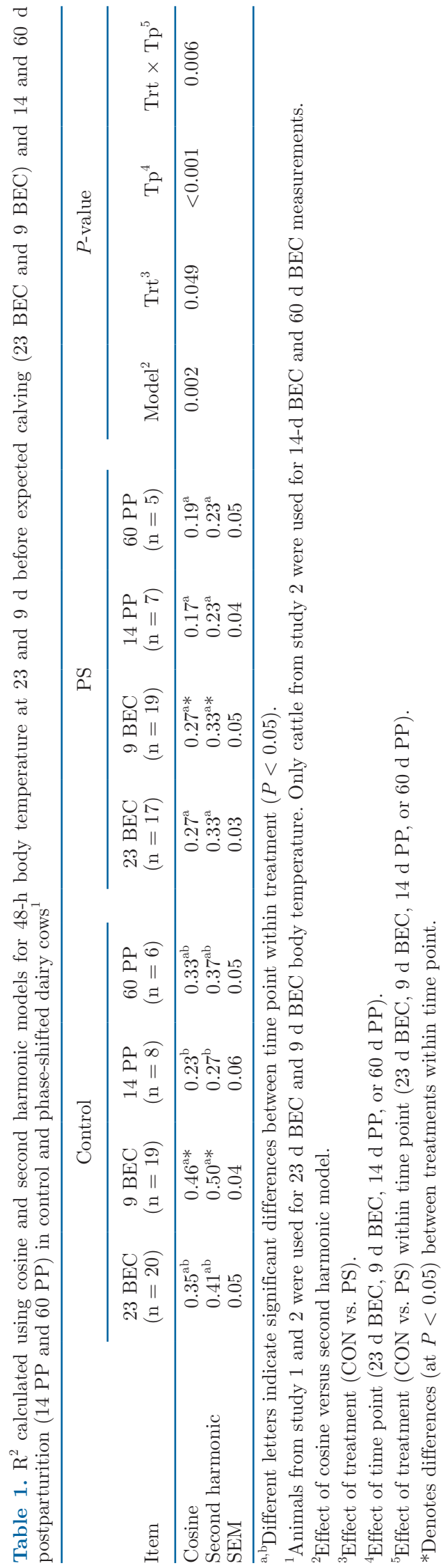

was evaluated (Table 1 ). The mean $\mathrm{R}^{2}$ across individual animals within treatments was lower (Table 1) than coefficient of regression of mean core body temperature data (Figure 1A-H) but supported that PS treatment decreased circadian rhythmicity and that circadian rhythms of core body temperature showed the greatest robustness at $1 \mathrm{wk}$ prepartum. The mesor (the rhythm-adjusted mean) of core body temperature was influenced $(P<0.0001)$ by the time point (Supplemental Table S2; https://doi.org/10.4231/KEHG-RN90; Casey et al., 2021a). The mesor of CON cows for body temperature was greater at $9 \mathrm{~d} \operatorname{BEC}\left(39.25 \pm 0.05^{\circ} \mathrm{C}\right)$ and $14 \mathrm{~d} \mathrm{PP}\left(39.31 \pm 0.07^{\circ} \mathrm{C}\right)$ than at $23 \mathrm{~d}$ BEC $(38.98$ $\left.\pm 0.05^{\circ} \mathrm{C}\right)$ and $60 \mathrm{~d} \mathrm{PP}\left(39.08 \pm 0.10^{\circ} \mathrm{C}\right)$. Core temperature mesor did not vary $(P>0.05)$ by time point in PS cows. The amplitude (the difference between the peak and the mesor) of core body temperature across all time points was greater $(P=0.005)$ in $\mathrm{CON}$ cows $(0.20$ $\left.\pm 0.02^{\circ} \mathrm{C}\right)$ compared with PS ones $\left(0.14 \pm 0.02^{\circ} \mathrm{C}\right)$.

\section{Changes in Morning Hormone Levels Across the Transition Period}

Mean morning blood CORT levels were not different between PS $(7.32 \pm 0.47 \mathrm{ng} / \mathrm{mL})$ and CON $(7.81 \pm$ $0.49 \mathrm{ng} / \mathrm{mL}$ ) cows (Figure 2A). Morning CORT concentration was also not different between preparturition $(\mathrm{CON}, 7.71 \pm 1.16 \mathrm{ng} / \mathrm{mL}$; PS, $7.01 \pm 1.00 \mathrm{ng} /$ $\mathrm{mL}$ ) and postparturition (CON, $6.15 \pm 0.60 \mathrm{ng} / \mathrm{mL}$; PS, $6.90 \pm 0.68 \mathrm{ng} / \mathrm{mL}$ ) periods $(\mathrm{CON}, P=0.19$; PS, $P=0.93)$. However, there was a fixed effect of the day of sampling $(P<0.01)$, and post hoc analysis showed that CORT concentration on $\mathrm{d} 35 \mathrm{BEC}, 0 \mathrm{PP}$, and 22 $\mathrm{PP}$ was higher in both treatments than on the rest of the days. Morning GH concentration was greater in PS cows than in CON $(P=0.01$; Figure $2 \mathrm{~B})$, and the treatment by day effect indicated that GH concentration was greater $(P<0.01)$ on $2 \mathrm{~d}$ BC in PS cows $(201.81 \pm 12.44 \mathrm{ng} / \mathrm{mL})$ than in CON $(102.62 \pm 16.46$ $\mathrm{ng} / \mathrm{mL}$ ). Day of sampling also affected morning $\mathrm{GH}$ levels, with it significantly $(P<0.05)$ higher on $2 \mathrm{~d}$ BC and $0 \mathrm{~d}$ PP than in all other day sampled. The overall effect of PS exposure was to increase morning MEL ( $P$ $<0.05$ ) levels, and posthoc analysis found MEL was $>1.5$-fold higher on $15 \mathrm{PP}$ and $22 \mathrm{PP}$ in PS than CON $(P<0.05$; Figure $2 \mathrm{C})$. Morning blood $\mathrm{P} 4$ concentration was not different between CON $(2.03 \pm 0.14 \mathrm{ng} / \mathrm{mL})$ and PS $(1.89 \pm 0.15 \mathrm{ng} / \mathrm{mL})$ treatments (Figure 2D). Progesterone concentration varied between days $(P<$ 0.01 ), with post hoc analysis indicating that preparturition $\mathrm{P} 4$ levels in both treatments were significantly $(P<0.05)$ higher than $0 \mathrm{PP}$ and all postparturition samples. The PS treatment had an overall effect of decreasing 5HT levels (CON, 3,716.25 $\pm 104.45 \mathrm{ng} /$ 
$\mathrm{mL}$; PS, $3,033.75 \pm 102.84 \mathrm{ng} / \mathrm{mL} ; P<0.01$; Figure $2 \mathrm{E})$. However, circulating levels of $5 \mathrm{HT}$ were not different between the preparturition and postparturition sampling periods in either of the treatments.

\section{Changes in Daily Oscillations of Hormones Across the Transition Period and the Effect of PS Treatment}

The mean CORT data at $23 \mathrm{~d}$ BEC had a better fit to the 2-component cosinor model for both treatments $\left(\mathrm{CON} \mathrm{R}{ }^{2}=0.51\right.$ and PS $\left.\mathrm{R}^{2}=0.61\right)$ compared with the single-component cosinor model $\left(\mathrm{CON} \mathrm{R}^{2}=0.10\right.$ and $\mathrm{PS} \mathrm{R}^{2}=0.30$; Figure 3) for both treatments. Mean CORT data from the $9 \mathrm{~d}$ BEC sampling had similar fits to both models (CON single-component cosinor $\mathrm{R}^{2}$ $=0.47$ and 2 -component cosinor $\mathrm{R}^{2}=0.52$; PS singlecomponent cosinor $\mathrm{R}^{2}=0.65$ and 2-component cosinor $\mathrm{R}^{2}=0.70$; Figure 3$)$. The fit of mean CORT data decreased for both treatments $\left(\mathrm{CON} \mathrm{R}^{2}=0.25\right.$; $\mathrm{PS} \mathrm{R}^{2}=$ 0.23 ) at 5 d BEC (Supplemental Figure S1; https://doi .org/10.4231/KEHG-RN90; Casey et al., 2021a). The $\mathrm{AIC}$ and BIC values were lower for 2-component cosinor in the $23 \mathrm{~d}$ BEC for both treatments (Supplemental Table S3; https://doi.org/10.4231/KEHG-RN90; Casey et al., 2021a).

Cortisol $\mathrm{R}^{2}$ fit of individual cows was influenced by time point $(P=0.015$, Table 2$)$. The fit of the data to the circadian rhythms was greater for individual cows at $9 \mathrm{~d}$ BEC $\left(\mathrm{R}^{2}=0.41 \pm 0.04\right)$ than in $23 \mathrm{~d}$ BEC $\left(\mathrm{R}^{2}=0.34 \pm 0.04\right)$ and $5 \mathrm{~d} \mathrm{PP}\left(\mathrm{R}^{2}=0.24 \pm 0.04\right)$. Furthermore, PS cows tended to have greater $\mathrm{R}^{2}(0.37$ $\pm 0.04 ; P=0.08)$ than $\mathrm{CON}$ cows $(0.24 \pm 0.04)$. Mesor, acrophase, or amplitude of CORT single-component cosinor rhythms were not different between treatments or time points (Supplemental Table S4; https://doi.org/ 10.4231/KEHG-RN90; Casey et al., 2021a). Area under the curve of CORT levels at $23 \mathrm{~d}$ BEC, $9 \mathrm{~d}$ BEC, and $5 \mathrm{~d}$ PP was also not different between treatments or time points (Supplemental Table S5; https://doi.org/ 10.4231/KEHG-RN90; Casey et al., 2021a).

Mean GH levels across all cows had low $\mathrm{R}^{2}(<0.50)$ values for all time points and treatments in both models (Supplemental Figure S2; https://doi.org/10.4231/ KEHG-RN90; Casey et al., 2021a). Growth hormone $\mathrm{R}^{2}$ of individual cows was not affected by treatment or time point (Table 2). Moreover, AIC and BIC for 2-component cosinor were greater than for the singlecomponent cosinor model. The mesor of GH concentration was greater at $9 \mathrm{~d}$ BEC $(41.98 \pm 13.27 \mathrm{ng} / \mathrm{mL}$; $P=0.002)$ than in $23 \mathrm{~d}$ BEC $(8.85 \pm 1.68 \mathrm{ng} / \mathrm{mL})$ and $5 \mathrm{~d}$ PP $(2.42 \pm 0.56 \mathrm{ng} / \mathrm{mL}$; Supplemental Table S6; https://doi.org/10.4231/KEHG-RN90; Casey et al., 2021a). The area under the curve of GH was influenced by time point in both treatments (Supplemental Table S5). Area under the curve of GH at $9 \mathrm{~d}$ BEC was greater than in $23 \mathrm{~d}$ BEC and $5 \mathrm{~d}$ PP.
A

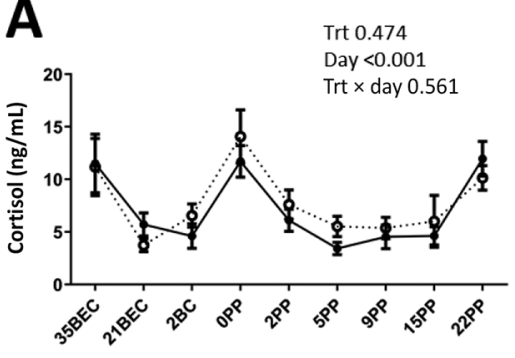

D

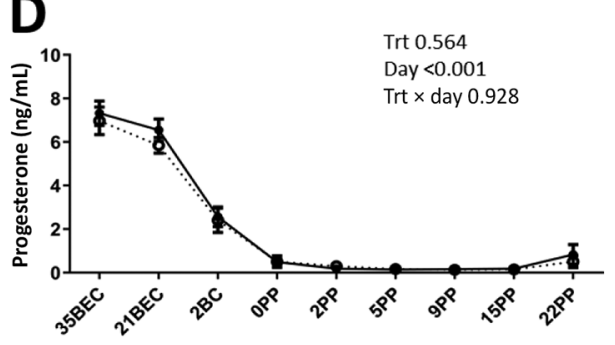

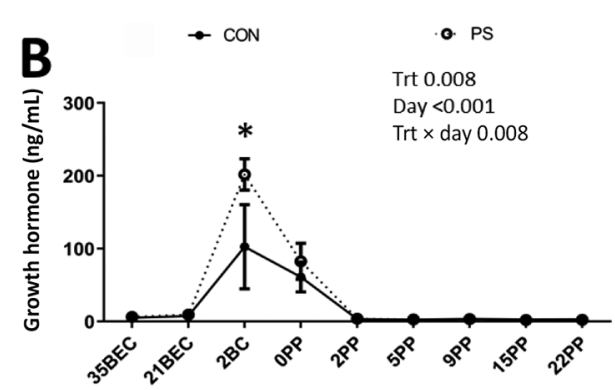
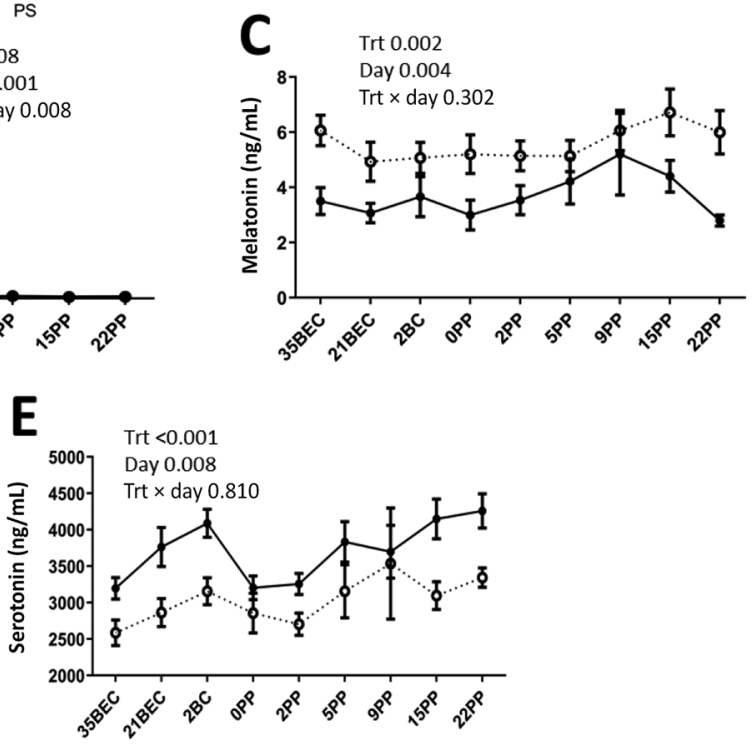

Figure 2. Plasma total cortisol (A), growth hormone (B), melatonin (C), progesterone (D), and serotonin (E) concentration in periparturient dairy cows exposed to control light (CON, solid lines and dots) or phase-shifted light (PS, dashed lines and empty dots). Thirty-two dairy cows were exposed during the preparturition period, starting at $5 \mathrm{wk}$ before expected calving $(\mathrm{BEC})$, to CON (n $=16 ; 16 \mathrm{~h}$ light: $8 \mathrm{~h}$ dark) or PS ( $\mathrm{n}$ $=16$; $16 \mathrm{~h}$ light: $8 \mathrm{~h}$ dark, lights shifted $6 \mathrm{~h}$ forward every $3 \mathrm{~d}$ ). Blood samples were collected at d 35 BEC, d 21 BEC, d 2 before calving (BC),

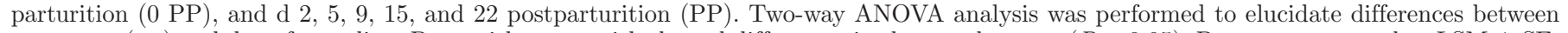
treatment (trt) and day of sampling. Days with an asterisk showed differences in the post hoc test $(P<0.05)$. Data are expressed as LSM \pm SE. 
A

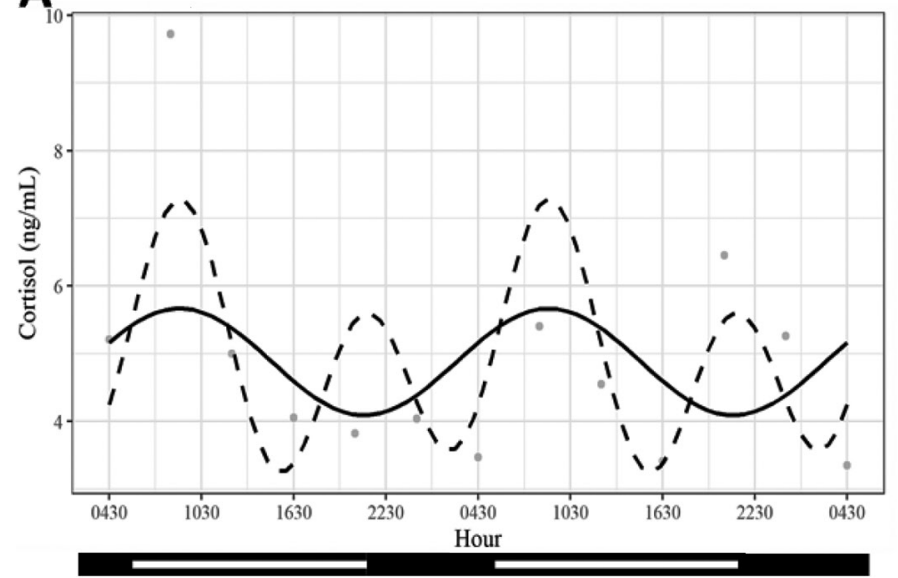

$\mathrm{C}_{12}$

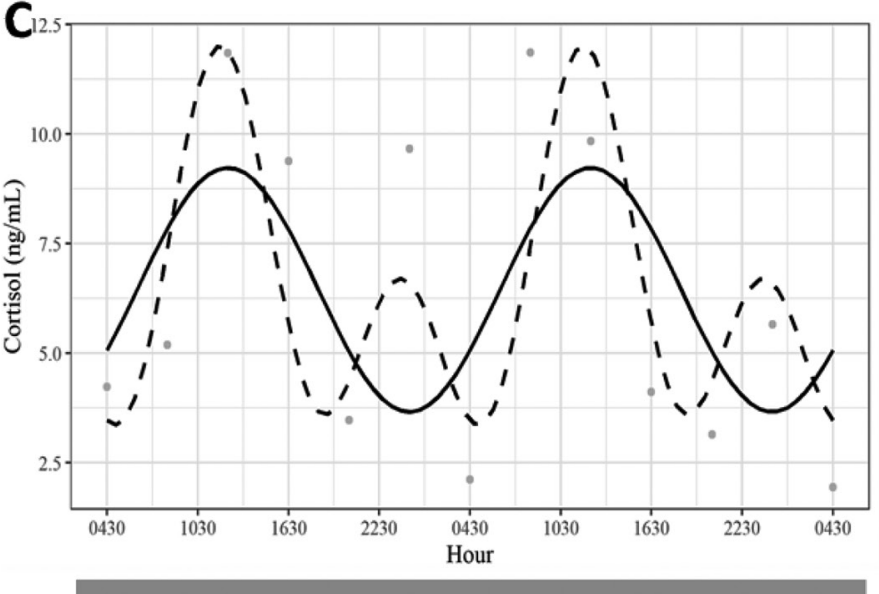

B

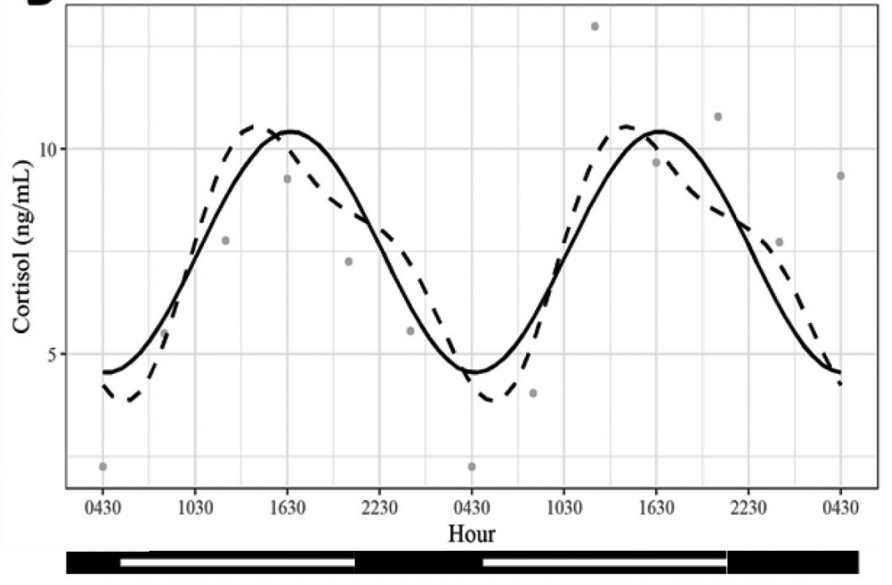

D

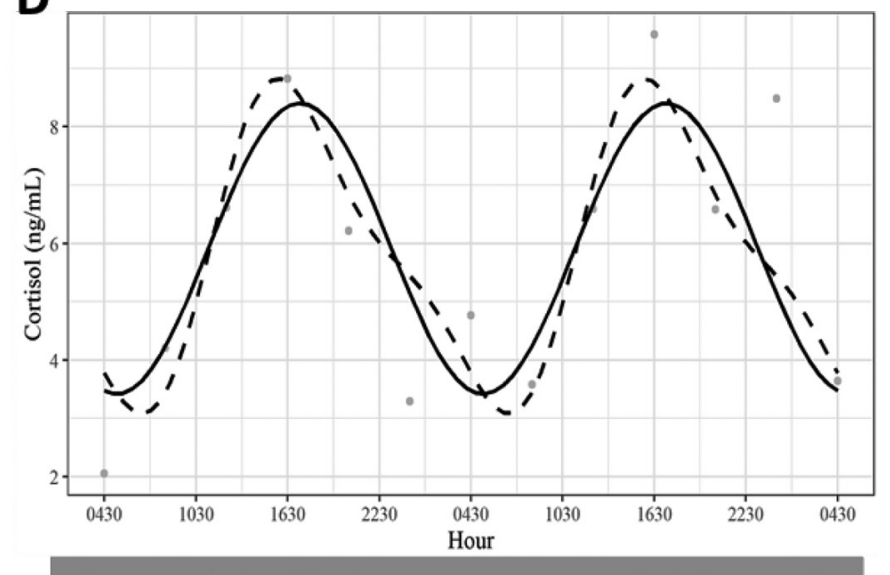

Figure 3. Total cortisol plasma concentration $(\mathrm{ng} / \mathrm{mL})$ in dairy cows at d 23 and 9 before expected calving (BEC). Five weeks before expected calving, cows were exposed to control treatment $(\mathrm{CON} ; \mathrm{n}=6 ; 16 \mathrm{~h}$ of light and $8 \mathrm{~h}$ of dark) or phase-shifted treatment (PS; $\mathrm{n}=6 ; 16$ $\mathrm{h}$ of light and $8 \mathrm{~h}$ dark, with the photophase shifted $6 \mathrm{~h}$ every $3 \mathrm{~d}$ ). Plasma samples were collected every $4 \mathrm{~h}$ during 48 -h periods at $23 \mathrm{~d}$ BEC (A, CON cows, $\mathrm{n}=6$; C, PS cows, $\mathrm{n}=6$ ), and $9 \mathrm{~d}$ BEC ( $\mathrm{B}$, CON cows, $\mathrm{n}=6$; $\mathrm{D}$, PS cows, $\mathrm{n}=6$ ). Gray dots represent the average of the observed data, solid black lines represent the single-component cosinor fitted curve, and dashed black lines represent the 2-component cosinor fitted curve. Bars under graph A and B represent the light (white) and dark (black) phases. Gray bars under graph C and D represent the shifted photoperiod for phase-shifted cows. (A) CON cows at $23 \mathrm{~d}$ BEC, $\mathrm{R}^{2}$ single-component cosinor model: 0.10; $\mathrm{R}^{2}$ 2-component cosinor model: 0.51 ; midline estimating statistic of rhythms (mesor): $4.96 \mathrm{ng} / \mathrm{mL}$; amplitude: $0.85 \mathrm{ng} / \mathrm{mL}$; acrophase: $20.07 \mathrm{~h}$; (B) CON cows at $9 \mathrm{~d}$ BEC, R ${ }^{2}$ singlecomponent cosinor model: $0.47 ; \mathrm{R}^{2}$ 2-component cosinor model: 0.52 ; mesor: $7.51 \mathrm{ng} / \mathrm{mL}$; amplitude: $2.89 \mathrm{ng} / \mathrm{mL}$; acrophase: $11.82 \mathrm{~h}$; (C) PS cows at $23 \mathrm{~d}$ BEC, $\mathrm{R}^{2}$ single-component cosinor model: 0.30; $\mathrm{R}^{2}$ 2-component cosinor model: 0.61; mesor: $6.58 \mathrm{ng} / \mathrm{mL}$; amplitude: $2.66 \mathrm{ng} / \mathrm{mL}$; acrophase: $16.36 \mathrm{~h}$; (D) PS cows at $9 \mathrm{~d}$ BEC, $\mathrm{R}^{2}$ single-component cosinor model: $0.65 ; \mathrm{R}^{2}$ 2-component cosinor model: $0.70 ;$ mesor: 5.89 ng/mL; amplitude: $2.54 \mathrm{ng} / \mathrm{mL}$; acrophase: $-11.20 \mathrm{~h}$.

Fit of mean MEL data of $\mathrm{CON} \mathrm{R}^{2}(0.83 \pm 0.03$; $P=0.001 ;$ Supplemental Figure S3; https://doi.org/ 10.4231/KEHG-RN90; Casey et al., 2021a) cows was greater than PS cows $\left(\mathrm{R}^{2}=0.72 \pm 0.05\right)$. In addition, there was an effect of treatment by time point $(P=$ 0.003). Post hoc analysis indicated that CON cows displayed greater $\mathrm{R}^{2}$ at $9 \mathrm{~d} \mathrm{BEC}$ and $5 \mathrm{~d} \mathrm{PP}$ than PS cows. Furthermore, PS cows, $23 \mathrm{~d}$ BEC $\mathrm{R}^{2}$ was greater $(0.84$ $\pm 0.03)$ than $9 \mathrm{~d}$ BEC $(0.69 \pm 0.07)$ and $5 \mathrm{~d} \mathrm{PP}(0.62 \pm$ 0.08; $P<0.05)$; however, CON cows did not show any difference between time points. The fit of individual animal hormone data to the single- and 2-component cosinor models was also evaluated and effect of treatment, time point, and cosinor models were compared (Table 2). The fit of MEL to both single- and 2-component cosinor models at time points $9 \mathrm{~d}$ BEC and $5 \mathrm{~d}$ PP was affected by exposure to light-dark phase shifts, as PS cattle had lower $\mathrm{R}^{2}$ values (Supplemental Figure S3; Table 2). There was no effect of time point on fit of MEL data to curves. The $\mathrm{R}^{2}$ of 2-component cosinor was different from single-component, supporting a better fit of data to these curves. Moreover, all the AIC and BIC calculated for the 2-component cosinor model were lower than those for the single-component cosinor 


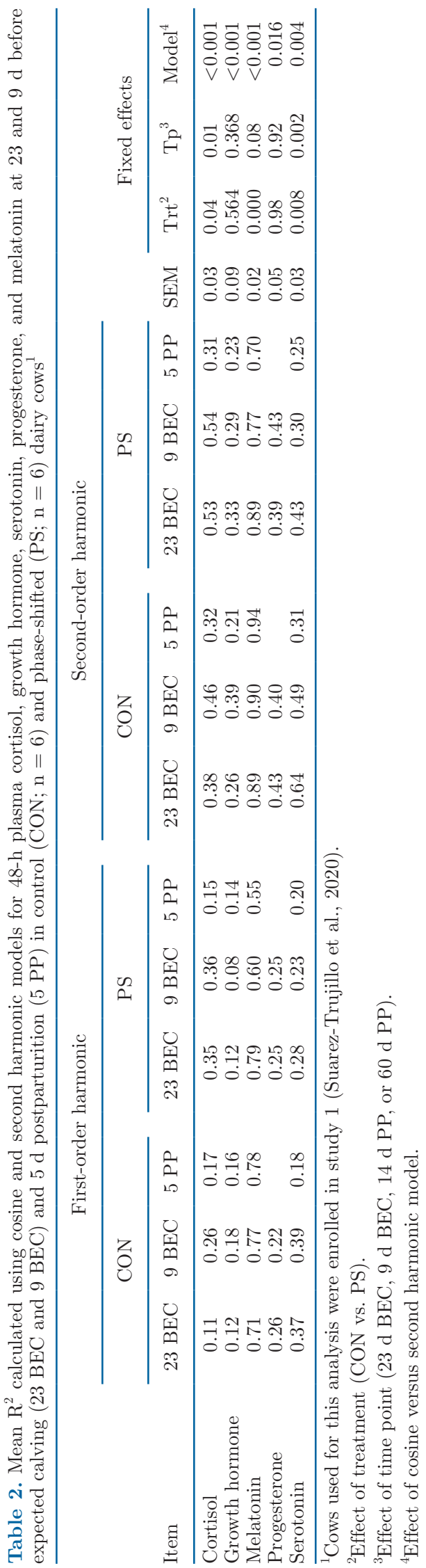

model (Supplemental Table S3). Analysis of the singlecomponent cosinor parameters found that acrophase was statistically different between treatments. The PS cows had an earlier acrophase $(5.70 \pm 0.80 \mathrm{~h})$ compared with CON cows (8.42 \pm 0.76 h; Supplemental Table S7; https://doi.org/10.4231/KEHG-RN90; Casey et al., 2021a). Area under the curve (AUC) of MEL was not affected by treatment. There was also no effect of time point on MEL AUC (Supplemental Table S5).

Mean $\mathrm{P} 4 \mathrm{R}^{2}$ was greater than 0.5 in $\mathrm{CON}$ cows at 23 $\mathrm{d}$ BEC in both models (0.61 in the single-component cosinor model and 0.71 in the 2-component cosinor model; Figure $4 \mathrm{~A}$ and B). However, at $9 \mathrm{~d}$ BEC, the $\mathrm{R}^{2}$ values were lower for both models in CON cows (0.11 in the single-component cosinor model and 0.34 in the 2-component cosinor model). In PS cows, the $\mathrm{R}^{2}$ calculated from mean $\mathrm{P} 4$ data showed low values $(<0.5)$ at $23 \mathrm{~d}$ BEC for the single-component cosinor $(0.17$; Figure 4A) and the 2-component cosinor (0.26), and at $9 \mathrm{~d}$ BEC in the single-component cosinor model (0.39), but the 2-component cosinor for PS cows in the $9 \mathrm{~d}$ BEC time period displayed a better $\mathrm{R}^{2}(0.62$, Figure $4 \mathrm{D})$. Analysis of fit of individual cow data P4 levels indicated that neither treatment nor time point had an effect on $\mathrm{R}^{2}$ of either model (Table 2). Analysis of $\mathrm{AIC}$ and BIC showed lower values for the 2-component cosinor model in both treatment (CON and PS) and time point ( $23 \mathrm{~d}$ BEC and $9 \mathrm{~d}$ BEC), except PS cows at $9 \mathrm{~d}$ BEC, which had lower values than the single-component cosinor model (Supplemental Table S3; https: //doi.org/10.4231/KEHG-RN90; Casey et al., 2021a). Mesor of $\mathrm{P} 4$ concentration varied $(P<0.05)$ by time point (Supplemental Table S8). Progesterone mesor at $23 \mathrm{~d}$ BEC was greater $(3.70 \pm 0.17 \mathrm{ng} / \mathrm{mL} ; P=0.001)$ than $9 \mathrm{~d}$ BEC $(2.70 \pm 0.11 \mathrm{ng} / \mathrm{mL})$. Progesterone AUC also varied by time point ( $23 \mathrm{~d}$ BEC vs. $9 \mathrm{~d}$ BEC). In both treatments, $23 \mathrm{~d}$ BEC $\mathrm{P} 4$ area under the curve $(364.16 \pm 81.33 \mathrm{ng} / \mathrm{mL})$ was greater $(P=0.004)$ than the $9 \mathrm{~d}$ BEC P4 AUC $(124.95 \pm 8.06 \mathrm{ng} / \mathrm{mL})$. Progesterone AUC was not affected by treatment.

Serotonin $\mathrm{R}^{2}$ calculated from the mean data showed a high value $(>0.5)$ in $\mathrm{CON}$ cows in the $23 \mathrm{~d} \mathrm{BEC}$ period in the 2-component cosinor model (0.61, Figure $5 \mathrm{~A})$ and in $9 \mathrm{~d}$ BEC in both models $\left(\mathrm{R}^{2}=0.64\right.$ in the single-component cosinor model and $\mathrm{R}^{2}=0.80$ in the 2-component cosinor model). The $\mathrm{R}^{2}$ values at $5 \mathrm{~d}$ $\mathrm{PP}$ in both treatments were lower than at 23 and $9 \mathrm{~d}$ BEC (Supplemental Table S2). The PS cows did not show a high $\mathrm{R}^{2}$ value $(<0.5)$ for either $23 \mathrm{~d}$ BEC or 9 $\mathrm{d}$ BEC periods. The AIC and BIC values were greater for the 2-component cosinor model, compared with the single-component cosinor model, in CON cows at $23 \mathrm{~d}$ and $9 \mathrm{~d}$ BEC, as well as PS cows at $9 \mathrm{~d}$ BEC (Supplemental Table S3). There was an effect of time point $(P$ 
A

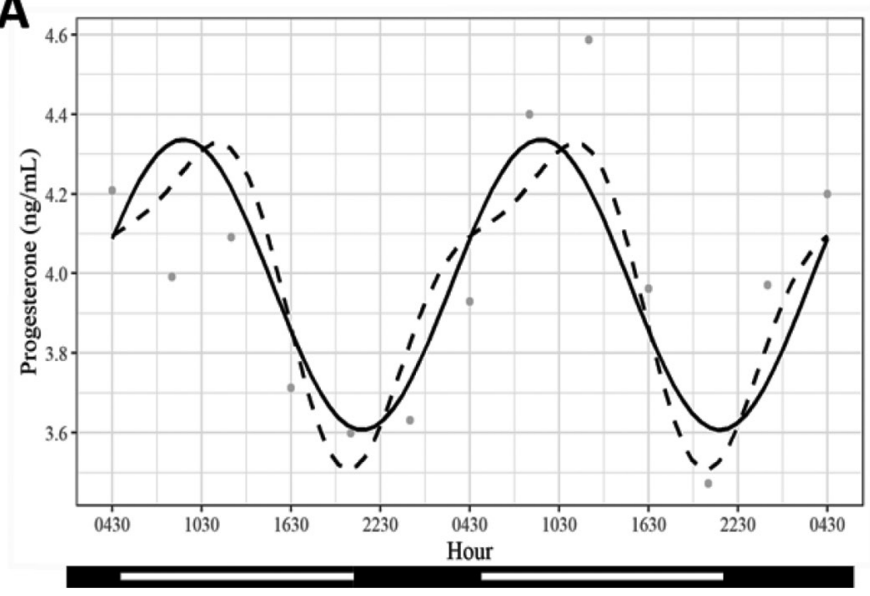

C

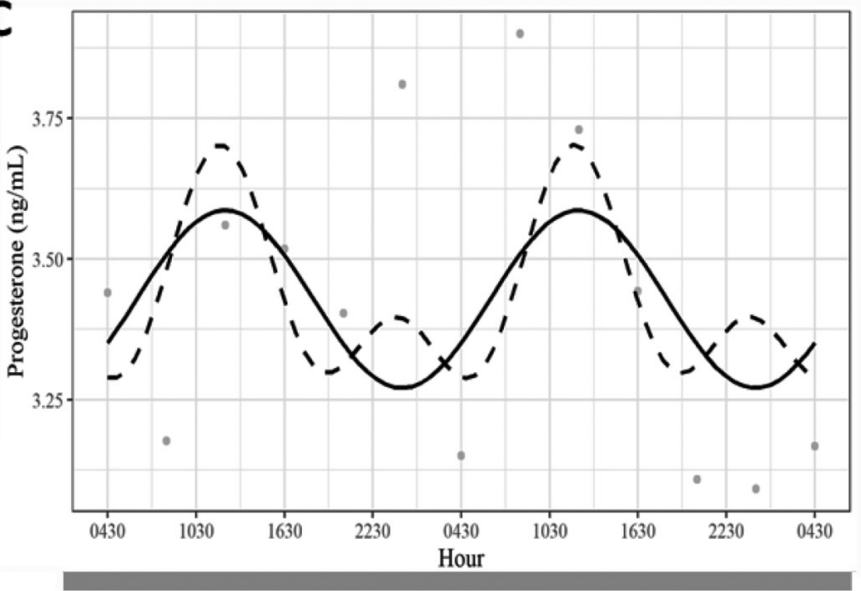

B

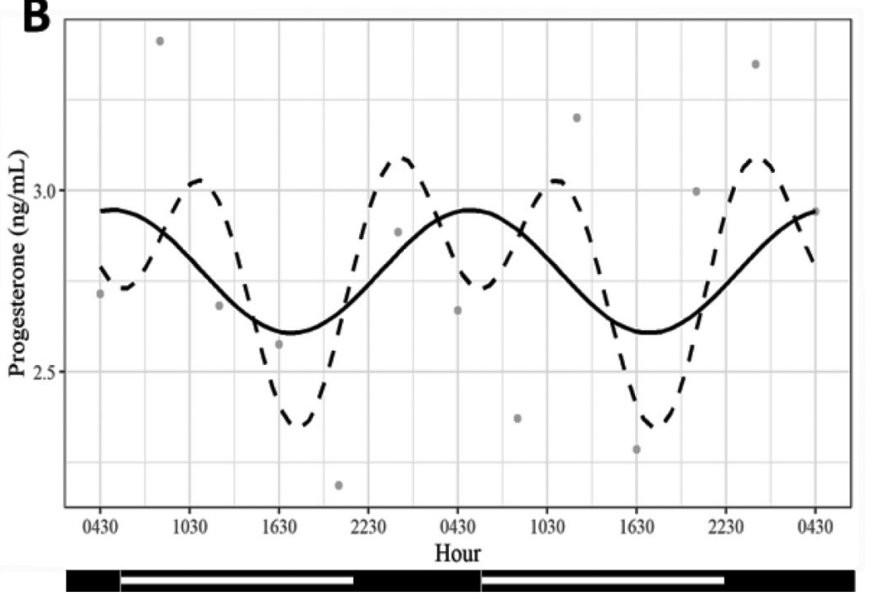

D

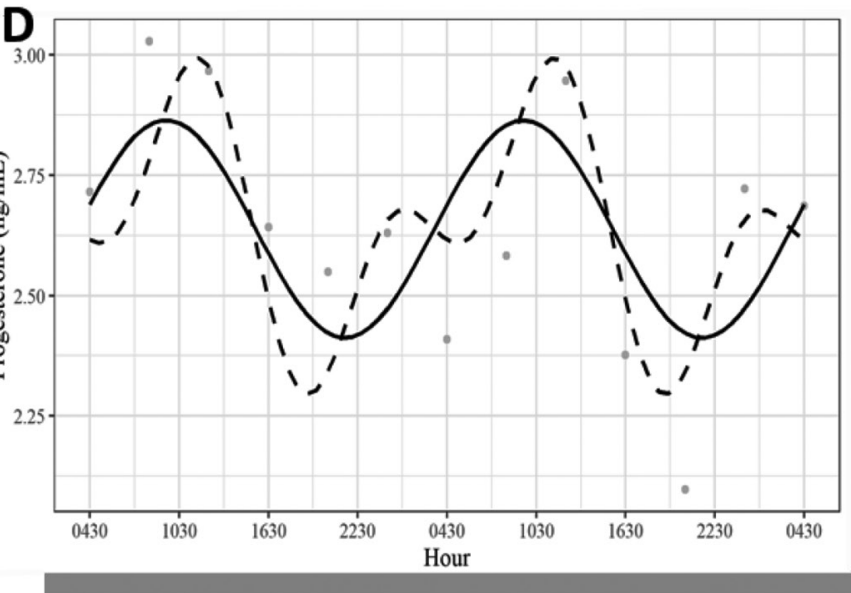

Figure 4. Progesterone plasma concentration $(\mathrm{ng} / \mathrm{mL})$ in dairy cows at d 23 and 9 before expected calving (BEC) and d 5 postparturition (PP). Five weeks before calving, cows were exposed to control treatment (CON; $\mathrm{n}=6 ; 16 \mathrm{~h}$ of light and $8 \mathrm{~h}$ of dark) or phase-shifted treatment (PS; $\mathrm{n}=6 ; 16 \mathrm{~h}$ of light and $8 \mathrm{~h}$ dark, with the photophase shifted $6 \mathrm{~h}$ every $3 \mathrm{~d}$ ). Plasma samples were collected every $4 \mathrm{~h}$ during 48 -h periods at $23 \mathrm{~d}$ BEC (A, CON cows, $\mathrm{n}=6$; C, PS cows, $\mathrm{n}=6$ ) and $9 \mathrm{~d}$ BEC (B, CON cows, $\mathrm{n}=6$; D, PS cows, $\mathrm{n}=6)$. Gray dots represent the average of the observed data, solid black lines represent the single-component cosinor fitted curve, and dashed black lines represent the 2-component cosinor fitted curve. Bars under graph A and B represent the light (white) and dark (black) phases. Gray bars under graph C and D represent the shifted photoperiod for phase-shifted cows. (A) CON cows at $23 \mathrm{~d}$ BEC, $\mathrm{R}^{2}$ single-component cosinor model: 0.65 ; $\mathrm{R}^{2} 2$-component cosinor model: 0.71; midline estimating statistic of rhythms (mesor): $3.97 \mathrm{ng} / \mathrm{mL}$; amplitude: $0.36 \mathrm{ng} / \mathrm{mL}$; acrophase: $19.23 \mathrm{~h}$; (B) CON cows at 9 d BEC, $\mathrm{R}^{2}$ single-component cosinor model: $0.11 ; \mathrm{R}^{2}$ 2-component cosinor model: 0.34; mesor: $2.79 \mathrm{ng} / \mathrm{mL}$; amplitude: $0.19 \mathrm{ng} / \mathrm{mL}$; acrophase: $23.27 \mathrm{~h}$; (C) PS cows at $23 \mathrm{~d}$ BEC, $\mathrm{R}^{2}$ single-component cosinor model: 0.17 ; $\mathrm{R}^{2}$ 2-component cosinor model: 0.26 ; mesor: $3.43 \mathrm{ng} / \mathrm{mL}$; amplitude: $0.15 \mathrm{ng} / \mathrm{mL}$; acrophase: $15.21 \mathrm{~h}$; and (D) PS cows at $9 \mathrm{~d}$ BEC, $\mathrm{R}^{2}$ single-component cosinor model: 0.39 ; $\mathrm{R}^{2}$ 2-component cosinor model: 0.62 ; mesor: $2.64 \mathrm{ng} / \mathrm{mL}$; amplitude: $0.23 \mathrm{ng} / \mathrm{mL}$; acrophase: $19.07 \mathrm{~h}$.

$<0.001)$ of $5 \mathrm{HT} \mathrm{R}^{2}$ when calculated from individual cows. None of the single-component cosinor parameters (mesor, amplitude, and acrophase; Supplemental Table S9; https://doi.org/10.4231/KEHG-RN90; Casey et al., 2021a) were different between treatments or time point. Serotonin AUC was not influenced by treatment or time point.

\section{DISCUSSION}

Daily rhythms were tested for fit of mean and individual cow data to single- and 2-component cosinor models. Traditionally, circadian rhythm modeling is performed using single-component cosinor models. However, single-component cosinor models can be restrictive when used to fit data of biological systems. Daily rhythms are often not symmetrical. The peak and nadir may not be exactly separated by $12 \mathrm{~h}$ and the amplitude and width of the peak may differ from those of the nadir. A multi-component cosinor introduces flexibility to the model and may better fit or describe asymmetrical biological rhythms (Wang and Brown, 1996; Madden et al., 2018). Single- and 2-component cosinor analysis of mean data across cows enabled elucidation of factors that may be influencing rhythms of body temperature and hormones in late pregnancy. 
A
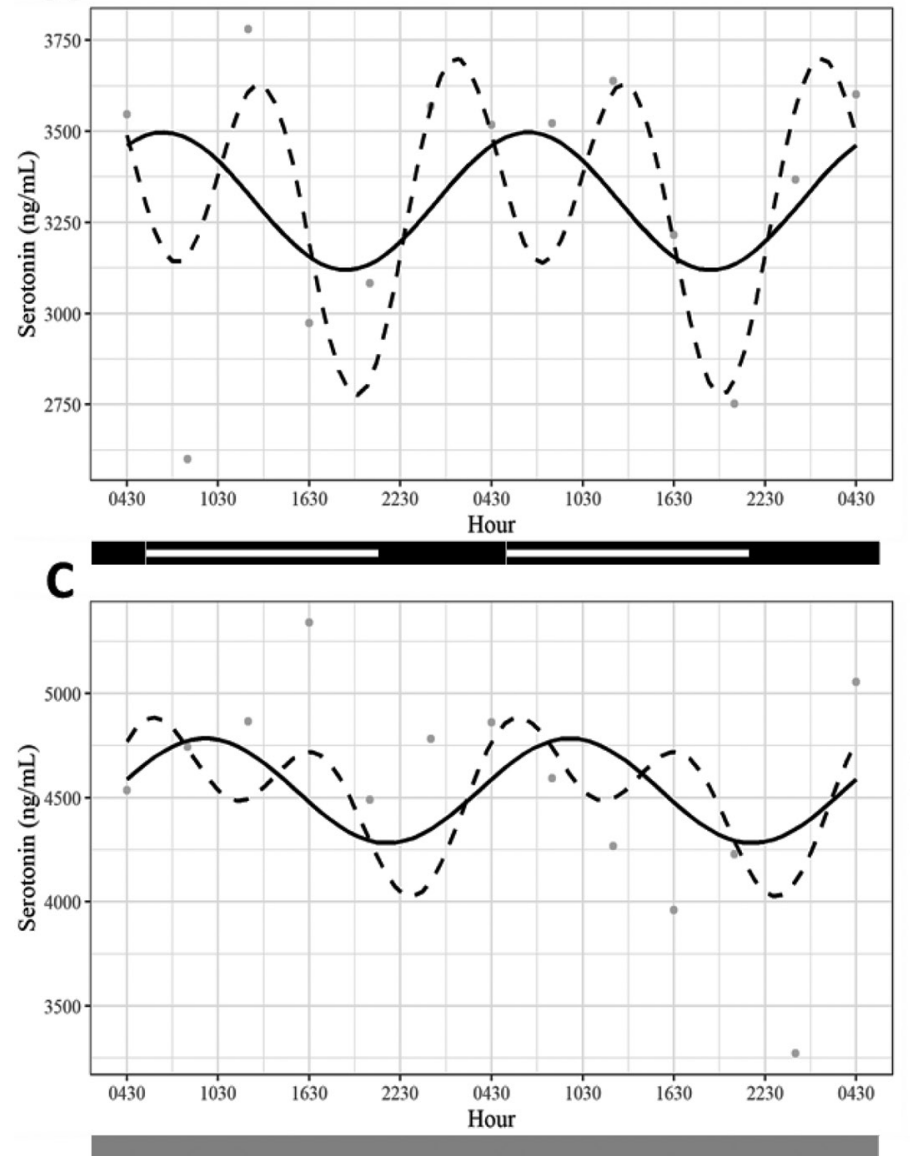

B
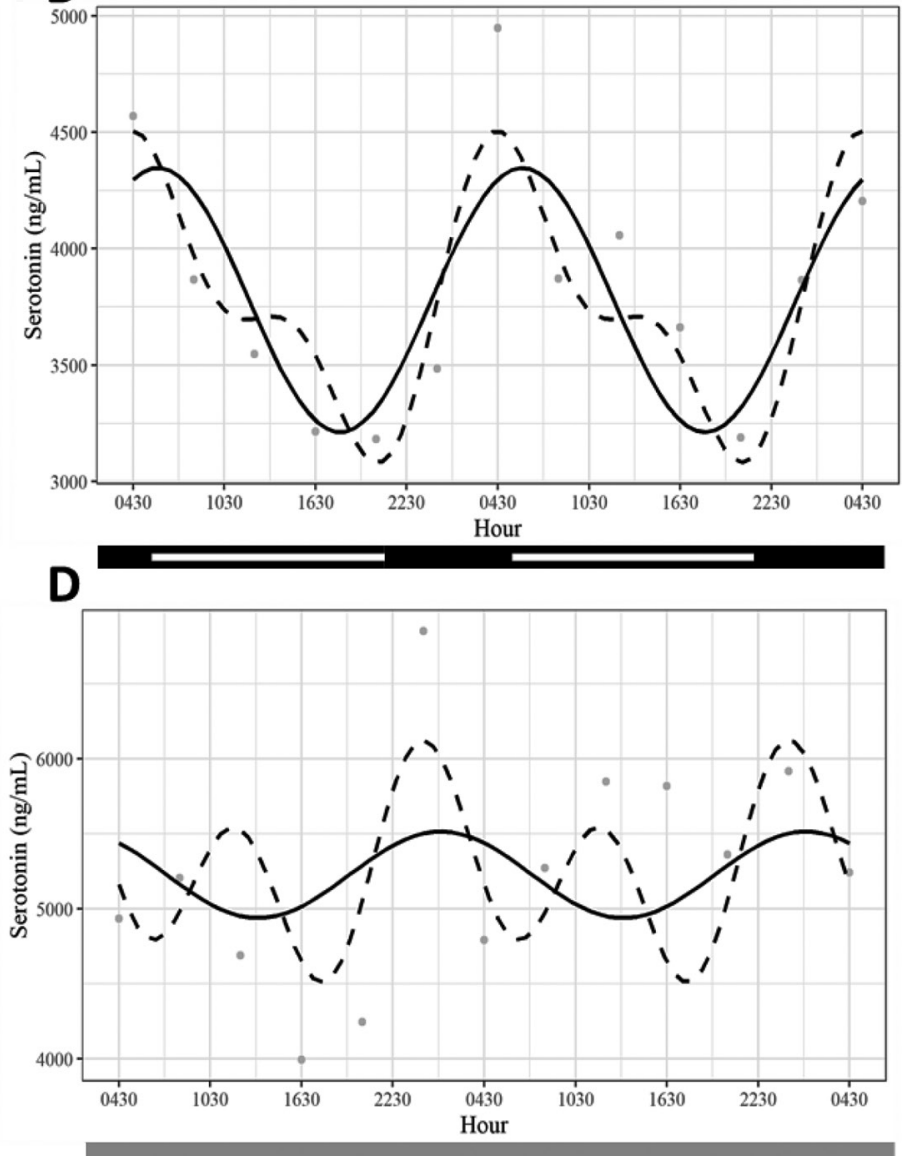

Figure 5. Serotonin plasma concentration $(\mathrm{ng} / \mathrm{mL})$ in dairy cows at d 23 and 9 before expected calving (BEC). Five weeks before expected calving, cows were exposed to control treatment $(\mathrm{CON} ; \mathrm{n}=6 ; 16 \mathrm{~h}$ of light and $8 \mathrm{~h}$ of dark) or phase-shifted treatment (PS; $\mathrm{n}=6 ; 16 \mathrm{~h}$ of light and $8 \mathrm{~h}$ dark, with the photophase shifted $6 \mathrm{~h}$ every $3 \mathrm{~d}$ ). Plasma samples were collected every $4 \mathrm{~h}$ during 48 -h periods at $23 \mathrm{~d}$ BEC (A, CON cows, $\mathrm{n}=6$; C, PS cows, $\mathrm{n}=6$ ) and $9 \mathrm{~d}$ BEC (B, CON cows, $\mathrm{n}=6 ; \mathrm{D}$, PS cows, $\mathrm{n}=6$ ). Gray dots represent the average of the observed data, solid black lines represent the single-component cosinor fitted curve, and dashed black lines represent the 2-component cosinor fitted curve. Bars under graph A and B represent the light (white) and dark (black) phases. Gray bars under graph C and D represent the shifted photoperiod for phase-shifted cows. (A) CON cows at $23 \mathrm{~d}$ BEC, $\mathrm{R}^{2}$ single-component cosinor model: $0.15 ; \mathrm{R}^{2}$ 2-component cosinor model: 0.60 ; midline estimating statistic of rhythms (mesor): $3,306.02 \mathrm{ng} / \mathrm{mL}$; amplitude: $185.28 \mathrm{ng} / \mathrm{mL}$; acrophase: $21.56 \mathrm{~h}$; (B) CON cows at $9 \mathrm{~d}$ BEC, $\mathrm{R}^{2}$ single-component cosinor model: 0.64; $\mathrm{R}^{2}$ 2-component cosinor model: 0.80; mesor: 3,762.56 ng/mL; amplitude: $536.44 \mathrm{ng} / \mathrm{mL}$; acrophase: $22.28 \mathrm{~h}$; (C) PS cows at $23 \mathrm{~d}$ BEC, $\mathrm{R}^{2}$ single-component cosinor model: 0.11; $\mathrm{R}^{2}$ 2-component cosinor model: 0.25 ; mesor: 4,518.09 ng/mL; amplitude: $246.15 \mathrm{ng} / \mathrm{mL}$; acrophase: $18.39 \mathrm{~h}$; (D) PS cows at $9 \mathrm{~d}$ BEC, $\mathrm{R}^{2}$ single-component cosinor model: 0.08; $\mathrm{R}^{2}$ 2-component cosinor model: 0.38; mesor: $5,250.88$ ng/ $\mathrm{mL}$; amplitude: $323.44 \mathrm{ng} / \mathrm{mL}$; acrophase: $2.49 \mathrm{~h}$.

It also led to development of the hypothesis that the master clock output cues become stronger, as parturition nears, with this reflected in more robust circadian rhythms of temperature and in turn more robust rhythms of CORT and 5HT.

Dramatic physiological changes occur in females in the preparation for birth, during parturition, and in the establishment of lactation. One of the most interesting observations made in this study was the strength of the fit of core body temperature data to circadian rhythms increased from $3 \mathrm{wk}$ to $1 \mathrm{wk}$ BEC. The circadian rhythm of core body temperature is a primary output of the central-master clock in the hypothalamus and functions to synchronize the timing of peripheral clocks (Buhr et al., 2010). In CON cattle, the increase in core body temperature circadian rhythms was associated with an increase in fit of circulating CORT and 5HT levels to circadian rhythms. These changes in daily oscillations of core body temperature and CORT and 5HT as cattle approach parturition can be interpreted as the revelation of underlying circadian rhythms due to changes in sleep and ingestive behaviors in the periparturient behavior, as discussed below. Alternatively, changes may be indicative of an increase in strength in the synchronizing signal from the central clock, or a combination of both. Disrupting the timing of the central clock 
by exposure to chronic light-dark PS decreased the fit of core body temperature to circadian rhythms in PS cattle and was related to longer gestation. The timing of the onset of labor and the hour of birth is related to time of day in many species (Longo and Yellon, 1988). Similar to our findings, others reported that exposing pregnant sheep to chronic light-dark PS increased gestation length (Varcoe et al., 2014). Thus, the loss of a strong central synchronizing cue may have resulted in prolonged gestation, and the increase in circadian rhythmicity of core body temperature and hormones in control cows may reflect synchronizing cues for this physiological event. Despite a general lower fit of core body temperature rhythms in PS animals, cows in this treatment also appeared to respond to a coordinating signal outside of the normal light-dark cycle.

Although the daily rhythm of core body temperature is controlled by the central clock (Buhr et al., 2010), it can be influenced by other factors like feeding time and activity (Verwey and Amir, 2009) as well as reproductive state (Schrader et al., 2009). A saddling of body temperature rhythms observed in CON cows at $23 \mathrm{~d}$ BEC captured in 2-component cosinor model is consistent with the food anticipatory response, which is marked by increased core body temperature in the hours leading up to the predictable mealtime (Verwey and Amir, 2009) and has been reported to occur in ruminants (Piccione et al., 2003). The better fit of temperature data to cosinor models at $9 \mathrm{~d}$ BEC versus other time points may be indicative of a synchronizing cue from central clock, and potentially explain the revelation of circadian rhythms in CORT and 5HT. Moreover, in CON cows, the fit of the body temperature data to either the single-component cosinor or 2-component cosinor model decreased in postparturition time points (14 and $60 \mathrm{~d}$ PP). This effect could be related to the changes in environment (move from tie-stalls to box-stall before calving and back to the tiestall after calving) and the beginning of milking twice a day. During milking, multiple hormones are released after the neuroendocrine stimulation. Some of those hormones such as oxytocin have shown thermoregulatory functions through targeting the hypothalamus (Kasahara et al., 2013). Phase-shifted cows displayed reduced $\mathrm{R}^{2}$ for temperature in the preparturition time points. This result demonstrates the effectiveness of the PS treatment on disrupting the circadian timing system at the level of the central controller in the master clock. Lack of a reference of a regular light-dark cycle to synchronize clocks in PS treatment likely led shifts in daily temperature to other influencers such as feeding and exercise. This supposition was indicated with an increase in body temperature right after the evening exercise $(1530 \mathrm{~h})$ and feeding time $(1600 \mathrm{~h})$ and the second peak of the 2-component cosinor matches with the morning exercise $(0430 \mathrm{~h})$ at $23 \mathrm{~d}$ BEC, rather than strong 24-h rhythms. Compared with the good fit that was observed in CON cows for P4 in $23 \mathrm{~d}$ BEC and $5 \mathrm{HT}$ in the $9 \mathrm{~d}$ BEC, PS cows did not follow those same patterns, suggesting that the disruption of the circadian system is related to the disruption of the normal daily fluctuations of those hormones.

The strong circadian rhythms of circulating MEL observed across both treatments reflect the acute sensitivity of light-regulated inhibition of synthesis of this hormone (Amaral et al., 2014), and so distinct rhythms of circulating MEL levels followed $24 \mathrm{~h}$ light-dark cycles. For CON cows, the 2-component cosinor model of MEL data better captured rise and fall around dark and light phase, as it allowed for lack of symmetry and may have better reflected $14 \mathrm{~h}$ L:10 h D photophase that cows were exposed to. Exposure to chronic lightdark PS affected MEL rhythms. Curves of mean data across all PS cows in the prepartum had broader or multiple peaks within a 24 -h period and lower amplitudes than those of CON cows. Time point had a trend for a difference in model fit. The CON cow $\mathrm{R}^{2}$ were highly similar between time points, whereas the PS cattle showed the greatest variation across time points, with numerical values decreasing from $23 \mathrm{~d}$ BEC to 5 d PP. This suggests that despite the cessation of treatment, MEL rhythms remained altered by treatment. The MEL levels were greater in PS than CON cows in once per day morning samples. In the prepartum period, higher MEL levels may have been due to sampling in the dark phase if cow sampling days fell on this phase shift. However, both treatments were on the control light-dark cycle in the PP, and $0600 \mathrm{~h}$ samples were taken $1 \mathrm{~h}$ after the start of the light phase. Thus, higher MEL levels in PS cows appear to be a carry-over effect of the treatment. Melatonin is a powerful antioxidant and plays a central role in metabolism (Amaral et al., 2014). Studies of other species found levels of MEL increased across pregnancy into the early PP and changes were postulated to function in the metabolic adaptations to these reproductive states (Tamura et al., 2008; Brockus et al., 2016). In the first study, PS cows produced more milk, whereas in the second study PS cows produced less milk. In the second study, once per day sampling found no difference in MEL between treatments (data not shown). Evaluation of the effect of PS on mammary development in the second study showed PS treatment decreased mammary development and increased expression of genes in liver and muscle related to oxidative stress (Casey et al., 2021b; McCabe et al., 2021a). One potential explanation of different study findings is the negative effect that PS treatment had on mammary epithelial proliferation and cellular 
stress in the liver and muscle was potentially negated by the positive effects of greater MEL levels in the first study (Suarez-Trujillo et al., 2020).

Changes in maternal CORT and P4 milieu drive many of the changes that occur to initiate parturition and the longitudinal profiles of circulating levels of $\mathrm{P} 4$ and CORT from 5 wk before expected calving through the PP period. Neither of these profiles were affected by exposure to chronic light-dark PS. Changes in circulating levels of total CORT across the course of the study were consistent with previous reports (Hudson et al., 1976) and capture the rise at parturition due to fetal CORT and CORT stress response to labor and delivery in the cow, followed by the return to basal levels in the first days PP. The high levels on $35 \mathrm{~d}$ BEC and $22 \mathrm{~d}$ $\mathrm{PP}$ versus other sampling days likely reflect the stress response of moving animals into experimental barns at $35 \mathrm{~d}$, and the stress response to moving into the freestall barn from the tie-stall barn. Although a strong circadian rhythm in CORT was detected at $1 \mathrm{wk}$ before expected calving, the fit of data to a circadian rhythm at 3 wk prepartum and $1 \mathrm{wk}$ PP was poor. This may have been due to our sampling protocol as using polynomial analysis of blood CORT levels captured every 15 min over a 48-h period, Lefcourt et al. (1993) were able to reveal weak circadian rhythms in mid-lactation dairy cows within dominant ultradian oscillations that occurred approximately every $2 \mathrm{~h}$. The lack of circadian rhythm in cows at $23 \mathrm{~d}$ BEC and $5 \mathrm{~d}$ PP time points is consistent with findings of Hudson et al. (1975), as well as those in late pregnant sheep (Apostolakis et al., 1993). Hudson et al. (1975) postulated that despite well-documented circadian rhythms of glucocorticoids in humans, rodents, and pigs, lack of diurnal rhythm in dairy cattle may be due to their unique sleep-wake structure. Lack of deep consolidated sleep in ruminants is hypothesized to be due to rumination, which requires additional time of consciousness. This supposition is supported by studies that found sheep entered deep sleep when fed chopped grass, whereas when sheep were fed unlimited hay they did not enter deep sleep (Morag, 1967). Recent studies of sleep structure in dairy cows showed it changed throughout the lactation cycle (Ternman et al., 2019). Total duration and number of bouts of rapid eye movement (REM) sleep as well as the duration of drowsing were greater at 2 wk before calving than during the second week of lactation. The REM sleep predominantly occurred at night versus the daytime, and the bout duration of REM was longer during nighttime compared with daytime. There was no effect of stage of lactation cycle on the duration of being awake or ruminating. The changes in daily oscillations of CORT observed in our study likely reflect these changes in sleep structure across the time points. Cows in this study decreased feed intake right around the 9 d BEC time point (Suarez-Trujillo et al., 2020), and rumination time was reported by others to be decreased in the periparturient period (Kovács et al., 2017), and therefore enable lower vigilance. Thus, it is probable that cattle slept more in the last week preparturition than during the third week, and allowed the revelation of underlying circadian rhythms observed at $9 \mathrm{~d}$ BEC.

The drop observed in circulating P4 from $21 \mathrm{~d}$ BEC to $\mathrm{d} 2 \mathrm{~d} \mathrm{BC}$ and $0 \mathrm{~d} \mathrm{PP}$ is consistent with previous reports (Goff et al., 2002). The drop in levels reflects luteolysis, which begins $3 \mathrm{~d}$ before calving (Wiltbank et al., 2016). Results regarding whether P4 exhibits circadian rhythms during pregnancy are mixed (Bates and Herzog, 2020). In nonpregnant, lactating dairy cows, ultradian patterns of $\mathrm{P} 4$ were described with 2 peaks in a 24-h period (Amann and Waberski, 2014). No evidence for circadian rhythms of $\mathrm{P} 4$ was found during varying stages of the estrous cycle in heifers (Hannan et al., 2010). However, late-gestation nonhuman primates were found to exhibit circadian rhythms of ovarian steroids, including P4, and myometrial contractions. Exposure to constant light did not affect rhythms nor did timed administration of MEL, suggesting that P4 rhythms are generated by endogenous clocks during pregnancy (Matsumoto et al., 1991). The finding that circadian disruption by exposure to constant light caused a drop in circulating P4 in pregnant ewes and their fetuses (Gao et al., 2016) supports circadian clock regulation of daily $\mathrm{P} 4$ rhythms. Idealized models of mean levels across all CON cows at $23 \mathrm{~d}$ BEC support that $\mathrm{P} 4$ showed circadian rhythms of concentration. Approximately $64 \%$ and $71 \%$ of the variation in P4 data could be explained by first and 2-component cosinor curves, whereas across individual animals $22 \%$ and $40 \%$ were explained, respectively. The lower fit of data to cosinor models of CON cows at $9 \mathrm{~d}$ BEC likely reflects that luteolysis had been initiated.

Serotoninergic and circadian systems interact and are reciprocally regulated in the central nervous system to regulate networks of homeostatic and homeorhetic processes (Ciarleglio et al., 2011). Serotonin produced in the central nervous system exhibits circadian rhythm antiphase from MEL and likely plays a key role in the integration of photic and nonphotic cues such as food availability (Kirsz and Zieba, 2012). Serotonin produced centrally does not cross the blood-brain barrier. Therefore, $5 \mathrm{HT}$ found in circulation is the result of the secretion by the epithelium of multiple organs including the intestine and mammary gland (Pai and Horseman, 2011). Outside the central nervous system, homeostatic and homeorhetic processes are also regulated by circadian and serotoninergic factors (Suarez-Trujillo and Casey, 2016). We found that in CON cows daily oscil- 
lations of peripheral 5HT better fit single- and 2-component cosinor models at $1 \mathrm{wk}$ before expected calving than at $3 \mathrm{wk}$. The better fit of circulating peripheral 5 HT levels at 1 wk versus 3 wk to 24 -h rhythms could, similar to the interpretation of CORT, reflect the revelation of underlying circadian rhythms controlled by clocks in peripheral tissues and a central synchronizing cue to time parturition. Also, it is interesting to note that PS cattle had lower levels of circulating 5HT. In our first study, PS-treated cows produced more milk than CON in the first 2 mo postparturition (SuarezTrujillo et al., 2020). The association of low circulating levels of $5 \mathrm{HT}$ in the first 2 wk postparturition with higher milk production in dairy cattle is consistent with the findings of others (Kessler et al., 2018; Kessler et al., 2019).

Growth hormone secretory patterns emerge following birth, and changes occur in secretion patterns throughout life. Growth hormone secretory patterns are coupled to growth, reproduction, and metabolism (Steyn and Ngo, 2017). For both PS and CON cows, morning concentration of GH increased around parturition, which is was consistent with the findings of others (Johke, 1979; Bernier-Dodier et al., 2011). The higher levels of GH in PS versus CON cows is also interesting to note, with no current understanding as to why this may have occurred. Daily GH secretory pattern in earlyand mid-lactation cows was found to be highly episodic (Vasilatos and Wangsness, 1981). Mid-lactation cows sampled every $15 \mathrm{~min}$ over $48 \mathrm{~h}$ showed good fit to circadian rhythms, with polynomial functions superior to single-component cosinor functions in terms of goodness of fit (Lefcourt et al., 1995). The lack of a good fit of our data to first or 2-component cosinor models may be due to the highly ultradian-pulsatile nature of GH secretion, which potentially prevented the realization of an underlying circadian rhythm.

For assessment of circadian rhythms, fit to singlecomponent cosinor models is traditionally used. However, biological data may need a more flexible model to better describe oscillations and capture daily rhythms that may not be symmetric. In this study, a 2-component cosinor was added to the single-component cosinor model to determine if this flexibility increased fit. Others (Lefcourt et al., 1993, 1995; Wang and Brown, 1996) also found a need for a more flexible model (for example, polynomial and semiparametric periodic spline) to fit rhythms of biological events that either show an ultradian rhythm or show asymmetry between the peak and nadir. We found that in almost all cases the fit of hormone and body temperature data was better for 2-component cosinor model. Moreover, mean data across all cows versus individual data showed better fit to single-component cosinor and 2-component cosinor models. There are advantages and disadvantages to analyzing fit of temporal data as means across animals versus using individual animal data. Use of data of individual cows better reflects the variability in the physiological events. However, it requires a greater number of individuals or a very rigorous sampling approach in a highly controlled environment to capture circadian rhythms (Lefcourt et al., 1993, 1995). Using mean data across animals to develop models may enable revelation of underlying rhythms that are masked when individual animals are analyzed. A good example of this in our analysis is the saddling in rhythms of body temperature data that were evident and related to the time of feed dispersion. This food anticipatory response at $23 \mathrm{~d}$ BEC was only evident when mean data were analyzed using 2-component cosinor analysis. The loss of this saddling at the $9 \mathrm{~d}$ BEC sampling period led us to surmise that potentially more dominant central cues may be synchronizing circadian rhythms to time parturition.

In addition to increasing the number of animals and more frequent sampling, our study could have been improved by measuring free CORT versus total CORT. Total CORT is circulating levels of CORT that is bound and unbound to CORT binding protein and does not reflect the pool of bioactive hormone. Total CORT is about 10-fold more than free CORT, and in the periparturient period the amount of free and total CORT do not necessarily parallel each other (Allolio et al., 1990; Jung et al., 2011). However, studies have found that total CORT does reflect changes in response to stress (Shutt and Fell, 1985) and physiological state (Hudson et al., 1976). Moreover, the sex of the fetus can affect maternal hormonal and metabolic status (Clifton, 2010). Studies with larger sample sizes need to be conducted to gain a better understanding of how offspring sex affects endocrine changes in the periparturient period. Another limitation of the study was that entrainment of control cow circadian rhythms to the light-dark cycles in the tie-stall was not assessed. Studies of humans and rodents indicate that it takes 5 to $6 \mathrm{~d}$ to adjust physiology to a 6 -h phase shift in the light-dark cycle (Yamazaki et al., 2000; Eastman et al., 2005). The largest shift in light-dark cycle phase was for cows enrolled in January. Based on timing of sunrise and sunset in relation to the light-dark cycle of the tie-stall facility, the light phase was shifted back $2.25 \mathrm{~h}$ and forward $2.25 \mathrm{~h}$ to extend light exposure from 11.5 to $16 \mathrm{~h}$ for these cows. The MEL and body temperature rhythms captured during the 23 d BEC sampling showed good fit to $24 \mathrm{~h}$ rhythms, with MEL changes highly coincident with phase of light-dark cycle. The data support that the control cows were fully acclimated to the light-dark cycles of the experimental barn. 
However, the shifting of light-dark phase every $3 \mathrm{~d}$ by $6 \mathrm{~h}$ prevented the PS cows from synchronizing their physiology to this environmental cue. The progressive loss of body temperature and MEL circadian rhythms between the 23 to $21 \mathrm{~d}$ BEC to 9 to $7 \mathrm{~d}$ BEC supports this conclusion and was the goal of the treatment.

In conclusion, the present work demonstrated that daily patterns of body temperature and circulating levels of CORT, GH, 5HT, MEL, and P4 change from 3 to $1 \mathrm{wk}$ before expected calving to 1 wk postparturition. Circadian rhythms of body temperature and multiple hormones appeared to become more robust (stronger) at 1 wk prepartum versus 3 wk prepartum and may indicate a synchronizing cue to time parturition. This supposition was supported by the finding the PS cattle, which had disrupted circadian rhythms, had longer gestation length. In the PP, circadian rhythmicity was lost or diminished for all hormones and body temperature in both treatments. Exposure to chronic light-dark PS in the prepartum period decreased the morning concentration of $5 \mathrm{HT}$ and increased the concentration of MEL, and this effect was carried over to the PP period. Together, findings indicate the importance of considering management factors that may affect circadian rhythms in dairy production systems, as they can affect physiology and potentially the timing of parturition.

\section{ACKNOWLEDGMENTS}

This work was supported by the Agriculture and Food Research Initiative (AFRI) competitive grant no. 2017-67015-26569 project accession no. 1011965 from the USDA National Institute of Food and Agriculture (Washington, DC). Support was also provided by Purdue University's Diversity Transformation Award (DTA), Big Ten Alliance Summer Undergraduate Research Opportunities, Bindley Bioscience Center, Metabolite Profiling Facility, and Jackeline Franco (Purdue University, West Lafayette, IN). The authors have not stated any conflicts of interest.

\section{REFERENCES}

Allolio, B., J. Hoffmann, E. A. Linton, W. Winkelmann, M. Kusche, and H. M. Schulte. 1990. Diurnal salivary cortisol patterns during pregnancy and after delivery: Relationship to plasma corticotrophin-releasing-hormone. Clin. Endocrinol. (Oxf.) 33:279-289. https://doi.org/10.1111/j.1365-2265.1990.tb00492.x.

Amann, R. P., and D. Waberski. 2014. Computer-assisted sperm analysis (CASA): capabilities and potential developments. Theriogenology 81:5-17.

Amaral, F. G., A. M. Castrucci, J. Cipolla-Neto, M. O. Poletini, N. Mendez, H. G. Richter, and M. T. Sellix. 2014. Environmental control of biological rhythms: Effects on development, fertility and metabolism. J. Neuroendocrinol. 26:603-612. https://doi.org/10 $.1111 /$ jne. 12144 .
Apostolakis, E. M., K. E. Rice, L. D. Longo, M. Seron-Ferre, and S. M. Yellon. 1993. Time of day of birth and absence of endocrine and uterine contractile activity rhythms in sheep. Am. J. Physiol. Endocrinol. Metab. 264:E534-E540. https://doi.org/10.1152/ ajpendo.1993.264.4.E534.

Bates, K., and E. D. Herzog. 2020. Maternal-fetal circadian communication during pregnancy. Front. Endocrinol. (Lausanne) 11:198. https://doi.org/10.3389/fendo.2020.00198.

Bauman, D. E. 2010. Homeorhesis: Past, present and future. Pages 1-20 in Elanco Science Symposium. Indianapolis, IN.

Bernier-Dodier, P., C. L. Girard, B. G. Talbot, and P. Lacasse. 2011. Effect of dry period management on mammary gland function and its endocrine regulation in dairy cows. J. Dairy Sci. 94:4922-4936. https://doi.org/10.3168/jds.2010-4116.

Bingham, C., B. Arbogast, G. C. Guillaume, J. K. Lee, and F. Halberg. 1982. Inferential statistical methods for estimating and comparing cosinor parameters. Chronobiologia 9:397-439.

Brockus, K. E., C. G. Hart, B. O. Fleming, T. Smith, S. H. Ward, and C. O. Lemley. 2016. Effects of supplementing Holstein heifers with dietary melatonin during late gestation on growth and cardiovascular measurements of their offspring. Reprod. Domest. Anim. 51:240-247. https://doi.org/10.1111/rda.12672.

Buhr, E. D., S.-H. Yoo, and J. S. Takahashi. 2010. Temperature as a universal resetting cue for mammalian circadian oscillators. Science 330:379-385. https://doi.org/10.1126/science.1195262.

Casey, T., J. P. Boerman, and A. Suárez Trujillo. 2021a. Supplemental tables and figures for effect of circadian system disruption on the concentration and daily oscillations of cortisol, progesterone, melatonin, serotonin, growth hormone, and core body temperature in periparturient dairy cattle. Purdue University Research Repository. https://doi.org/10.4231/KEHG-RN90.

Casey, T., J. Crodian, A. Suárez-Trujillo, E. Erickson, B. Weldon, K. Crow, S. Cummings, Y. Chen, A. Shamay, S. J. Mabjeesh, and K. Plaut. 2016. CLOCK regulates mammary epithelial cell growth and differentiation. Am. J. Physiol. Regul. Integr. Comp. Physiol. 311:R1125-R1134. https://doi.org/10.1152/ajpregu.00032.2016.

Casey, T., A. M. Suarez-Trujillo, C. McCabe, L. Beckett, R. Klopp, L. Brito, V. M. Rocha Malacco, S. Hilger, S. S. Donkin, J. Boerman, and K. Plaut. 2021b. Transcriptome analysis reveals disruption of circadian rhythms in late gestation dairy cows may increase risk for fatty liver and reduced mammary remodeling. Physiol. Genomics 53:441-455. https://doi.org/10.1152/physiolgenomics .00028 .2021 .

Casey, T., H. Sun, A. Suarez-Trujillo, J. Crodian, L. Zhang, K. Plaut, H. J. Burgess, S. Dowden, D. M. Haas, and A. Ahmed. 2020. Pregnancy rest-activity patterns are related to salivary cortisol rhythms and maternal-fetal health indicators in women from a disadvantaged population. PLoS One 15:e0229567. https://doi.org/ 10.1371/journal.pone.0229567.

Ciarleglio, C. M., H. E. Resuehr, and D. G. McMahon. 2011. Interactions of the serotonin and circadian systems: Nature and nurture in rhythms and blues. Neuroscience 197:8-16. https://doi.org/10 .1016/j.neuroscience.2011.09.036.

Clifton, V. L. 2010. Review: Sex and the human placenta: Mediating differential strategies of fetal growth and survival. Placenta 31(Suppl):S33-S39. https://doi.org/10.1016/j.placenta.2009.11 .010 .

Cornelissen, G. 2014. Cosinor-based rhythmometry. Theor. Biol. Med. Model. 11:16. https://doi.org/10.1186/1742-4682-11-16.

Davidson, A. J., O. Castanon-Cervantes, T. L. Leise, P. C. Molyneux, and M. E. Harrington. 2009. Visualizing jet lag in the mouse suprachiasmatic nucleus and peripheral circadian timing system. Eur. J. Neurosci. 29:171-180. https://doi.org/10.1111/j.1460-9568 .2008.06534.x.

Duffield, T. 2007. Peripartum metabolic monitoring. Pages 213-218 in AABP Proceedings 40. American Association of Bovine Practitioners.

Duffield, T., K. Lissemore, B. McBride, and K. Leslie. 2009. Impact of hyperketonemia in early lactation dairy cows on health and production. J. Dairy Sci. 92:571-580. https://doi.org/10.3168/jds .2008-1507. 
Eastman, C. I., C. J. Gazda, H. J. Burgess, S. J. Crowley, and L. F. Fogg. 2005. Advancing circadian rhythms before eastward flight: A strategy to prevent or reduce jet lag. Sleep 28:33-44. https://doi .org/10.1093/sleep/28.1.33.

Fernández, J. R., R. C. Hermida, and A. Mojón. 2009. Chronobiological analysis techniques. Application to blood pressure. Philos. Trans. Royal Soc. Math. Phys. Eng. Sci. 367:431-445.

Gao, Q., J. Lv, W. Li, P. Zhang, J. Tao, and Z. Xu. 2016. Disrupting the circadian photo-period alters the release of follicle-stimulating hormone, luteinizing hormone, progesterone, and estradiol in maternal and fetal sheep. J. Reprod. Dev. 62:487-493. https://doi .org/10.1262/jrd.2016-009.

Goff, J. P., K. Kimura, and R. L. Horst. 2002. Effect of mastectomy on milk fever, energy, and vitamins A, E, and beta-carotene status at parturition. J. Dairy Sci. 85:1427-1436. https://doi.org/10.3168/ jds.S0022-0302(02)74210-0.

Goldbeter, A. 2008. Biological rhythms: Clocks for all times. Curr. Biol. 18:R751-R753. https://doi.org/10.1016/j.cub.2008.06.044.

Goldbeter, A., C. Gérard, D. Gonze, J. C. Leloup, and G. Dupont. 2012. Systems biology of cellular rhythms. FEBS Lett. 586:29552965. https://doi.org/10.1016/j.febslet.2012.07.041.

Hannan, M. A., M. J. Fuenzalida, M. A. R. Siddiqui, M. Shamsuddin, M. A. Beg, and O. J. Ginther. 2010. Diurnal variation in LH and temporal relationships between oscillations in $\mathrm{LH}$ and progesterone during the luteal phase in heifers. Theriogenology 74:1491-1498. https://doi.org/10.1016/j.theriogenology.2010.06.021.

Hanon, E. A., G. A. Lincoln, J.-M. Fustin, H. Dardente, M. MassonPévet, P. J. Morgan, and D. G. Hazlerigg. 2008. Ancestral TSH mechanism signals summer in a photoperiodic mammal. Curr. Biol. 18:1147-1152. https://doi.org/10.1016/j.cub.2008.06.076.

Hudson, S., M. Mullford, W. G. Whittlestone, and E. Payne. 1976. Bovine plasma corticoids during parturition. J. Dairy Sci. 59:744746. https://doi.org/10.3168/jds.S0022-0302(76)84267-1.

Hudson, S., M. Mullord, W. G. Whittlestone, and E. Payne. 1975. Diurnal variations in blood cortisol in the dairy cow. J. Dairy Sci. 58:30-33. https://doi.org/10.3168/jds.S0022-0302(75)84513-9.

Johke, T. 1979. Studies of prolactin and growth hormone secretion in dairy cattle by radioimmunoassay. Jarq-Japan Agric. Res. Q. 13:134-137.

Jung, C., J. T. Ho, D. J. Torpy, A. Rogers, M. Doogue, J. G. Lewis, R. J. Czajko, and W. J. Inder. 2011. A Longitudinal study of plasma and urinary cortisol in pregnancy and postpartum. J. Clin. Endocrinol. Metab. 96:1533-1540. https://doi.org/10.1210/jc.2010 -2395 .

Kasahara, Y., K. Sato, Y. Takayanagi, H. Mizukami, K. Ozawa, S. Hidema, K.-H. So, T. Kawada, N. Inoue, I. Ikeda, S.-G. Roh, K. Itoi, and K. Nishimori. 2013. Oxytocin receptor in the hypothalamus is sufficient to rescue normal thermoregulatory function in male oxytocin receptor knockout mice. Endocrinology 154:43054315. https://doi.org/10.1210/en.2012-2206.

Kessler, E. C., S. K. Wall, L. L. Hernandez, R. M. Bruckmaier, and J. J. Gross. 2018. Short communication: Circulating serotonin is related to the metabolic status and lactational performance at the onset of lactation in dairy cows. J. Dairy Sci. 101:11455-11460. https://doi.org/10.3168/jds.2018-14626.

Kessler, E. C., S. K. Wall, L. L. Hernandez, J. J. Gross, and R. M. Bruckmaier. 2019. Short communication: Mammary gland tight junction permeability after parturition is greater in dairy cows with elevated circulating serotonin concentrations. J. Dairy Sci. 102:1768-1774. https://doi.org/10.3168/jds.2018-15543.

Kirsz, K., and D. A. Zieba. 2012. A review on the effect of the photoperiod and melatonin on interactions between ghrelin and serotonin. Gen. Comp. Endocrinol. 179:248-253. https://doi.org/10 .1016/j.ygcen.2012.08.025.

Kovács, L., F. L. Kézér, F. Ruff, and O. Szenci. 2017. Rumination time and reticuloruminal temperature as possible predictors of dystocia in dairy cows. J. Dairy Sci. 100:1568-1579. https://doi.org/10 $.3168 /$ jds.2016-11884

Kuljis, D. A., D. H. Loh, D. Truong, A. M. Vosko, M. L. Ong, R. McClusky, A. P. Arnold, and C. S. Colwell. 2013. Gonadal- and sex-chromosome-dependent sex differences in the circadian system.
Endocrinology 154:1501-1512. https://doi.org/10.1210/en.2012 $-1921$.

Lefcourt, A. M., J. Bitman, S. Kahl, and D. L. Wood. 1993. Circadian and ultradian rhythms of peripheral cortisol concentrations in lactating dairy cows. J. Dairy Sci. 76:2607-2612. https://doi.org/10 $.3168 /$ jds.S0022-0302(93)77595-5.

Lefcourt, A. M., J. Bitman, D. L. Wood, and R. M. Akers. 1995. Circadian and ultradian rhythms of peripheral growth hormone concentrations in lactating dairy cows. Domest. Anim. Endocrinol. 12:247-256. https://doi.org/10.1016/0739-7240(95)00022-7.

Longo, L. D., and S. M. Yellon. 1988. Biological timekeeping during pregnancy and the role of circadian rhythms in parturition. Pages 173-192 in The Endocrine Control of the Fetus. W. Künzel and A. Jensen, ed. Springer.

Madden, J. M., L. D. Browne, X. Li, P. M. Kearney, and A. P. Fitzgerald. 2018. Morning surge in blood pressure using a random-effects multiple-component cosinor model. Stat. Med. 37:1682-1695. https://doi.org/10.1002/sim.7607.

Matsumoto, T., D. L. Hess, K. M. Kaushal, G. J. Valenzuela, S. M. Yellon, and C. A. Ducsay. 1991. Circadian myometrial and endocrine rhythms in the pregnant rhesus macaque: Effects of constant light and timed melatonin infusion. Am. J. Obstet. Gynecol. 165:1777-1784. https://doi.org/10.1016/0002-9378(91)90032-M.

McCabe, C. J., U. K. Aryal, T. Casey, and J. Boerman. 2021a. Impact of exposure to chronic light-dark phase shifting circadian rhythm disruption on muscle proteome in periparturient dairy cows. Proteomes 9:35. https://doi.org/10.3390/proteomes9030035.

McCabe, C. J., A. Suarez-Trujillo, K. A. Teeple, T. M. Casey, and J. P. Boerman. 2021b. Chronic prepartum light-dark phase shifts in cattle disrupt circadian clocks, decrease insulin sensitivity and mammary development, and are associated with lower milk yield through 60 days postpartum. J. Dairy Sci. 104:2422-2437. https:/ /doi.org/10.3168/jds.2020-19250.

Morag, M. 1967. Influence of diet on the behaviour pattern of sheep. Nature 213:110. https://doi.org/10.1038/213110a0.

Moškon, M. 2020. CosinorPy: A python package for cosinor-based rhythmometry. BMC Bioinformatics 21:485. https://doi.org/10 $.1186 / \mathrm{s} 12859-020-03830-\mathrm{w}$.

Olcese, J. 2014. Circadian clocks and pregnancy. Front. Endocrinol. (Lausanne) 5:123.

Pai, V. P., and N. D. Horseman. 2011. Multiple cellular responses to serotonin contribute to epithelial homeostasis. PLoS One 6:e17028. https://doi.org/10.1371/journal.pone.0017028.

Papagiannakopoulos, T., M. R. Bauer, S. M. Davidson, M. Heimann, L. Subbaraj, A. Bhutkar, J. Bartlebaugh, M. G. Vander Heiden, and T. Jacks. 2016. Circadian rhythm disruption promotes lung tumorigenesis. Cell Metab. 24:324-331. https://doi.org/10.1016/ j.cmet.2016.07.001.

Piccione, G., G. Caola, and R. Refinetti. 2003. Circadian rhythms of body temperature and liver function in fed and food-deprived goats. Comp. Biochem. Physiol. A Mol. Integr. Physiol. 134:563572. https://doi.org/10.1016/S1095-6433(02)00362-8.

Pinto-Santini, L., and R. Ungerfeld. 2019. The phase of the estrous cycle modifies the endocrine, metabolic and behavior rhythms in ewes. Physiol. Behav. 204:324-335. https://doi.org/10.1016/j .physbeh.2019.03.011.

Reddy, A. B., M. D. Field, E. S. Maywood, and M. H. Hastings. 2002. Differential resynchronisation of circadian clock gene expression within the suprachiasmatic nuclei of mice subjected to experimental jet lag. J. Neurosci. 22:7326-7330. https://doi.org/10.1523/ JNEUROSCI.22-17-07326.2002

Refinetti, R., G. Cornélissen, and F. Halberg. 2007. Procedures for numerical analysis of circadian rhythms. Biol. Rhythm Res. 38:275325. https://doi.org/10.1080/09291010600903692.

Reid, K. J., F. L. Facco, W. A. Grobman, C. B. Parker, M. Herbas, S. Hunter, R. M. Silver, R. C. Basner, G. R. Saade, G. W. Pien, S. Manchanda, J. M. Louis, C. L. Nhan-Chang, J. H. Chung, D. A. Wing, H. N. Simhan, D. M. Haas, J. Iams, S. Parry, and P. C. Zee. 2017. Sleep during pregnancy: The nuMoM2b pregnancy and sleep duration and continuity study. Sleep 40. https://doi.org/10 $.1093 /$ sleep/zsx045. 
Schrader, J. A., E. J. Walaszczyk, and L. Smale. 2009. Changing patterns of daily rhythmicity across reproductive states in diurnal female Nile grass rats (Arvicanthis niloticus). Physiol. Behav. 98:547-556. https://doi.org/10.1016/j.physbeh.2009.08.012.

Shutt, D. A., and L. R. Fell. 1985. Comparison of total and free cortisol in bovine serum and milk or colostrum. J. Dairy Sci. 68:1832-1834. https://doi.org/10.3168/jds.S0022-0302(85)81035-3.

Skinner, N. J., M. Z. Rizwan, D. R. Grattan, and A. Tups. 2019. Chronic light cycle disruption alters central insulin and leptin signaling as well as metabolic markers in male mice. Endocrinology 160:2257-2270. https://doi.org/10.1210/en.2018-00935.

Skouteris, H., E. H. Wertheim, C. Germano, S. J. Paxton, and J. Milgrom. 2009. Assessing sleep during pregnancy: A study across two time points examining the Pittsburgh Sleep Quality Index and associations with depressive symptoms. Womens Health Issues 19:45-51. https://doi.org/10.1016/j.whi.2008.10.004.

Steyn, F. J., and S. T. Ngo. 2017. Endocrine rhythms of growth hormone release: Insights from animal studies. Best Pract. Res. Clin. Endocrinol. Metab. 31:521-533. https://doi.org/10.1016/j.beem 2017.10.009

Suárez-Trujillo, A., and T. M. Casey. 2016. Serotoninergic and circadian systems: Driving mammary gland development and function. Front. Physiol. 7:301. https://doi.org/10.3389/fphys.2016.00301.

Suarez-Trujillo, A., G. Wernert, H. Sun, T. S. Steckler, K. Huff, S. Cummings, J. Franco, R. N. Klopp, J. R. Townsend, M. Grott, J. S. Johnson, K. Plaut, J. P. Boerman, and T. M. Casey. 2020. Exposure to chronic light-dark phase shifts during the prepartum nonlactating period attenuates circadian rhythms, decreases blood glucose, and increases milk yield in the subsequent lactation. J. Dairy Sci. 103:2784-2799. https://doi.org/10.3168/jds.2019-16980.

Tamura, H., Y. Nakamura, M. P. Terron, L. J. Flores, L. C. Manchester, D.-X. Tan, N. Sugino, and R. J. Reiter. 2008. Melatonin and pregnancy in the human. Reprod. Toxicol. 25:291-303. https://doi .org/10.1016/j.reprotox.2008.03.005.

Ternman, E., E. Nilsson, P. P. Nielsen, M. Pastell, L. Hänninen, and S. Agenäs. 2019. Rapid eye movement sleep time in dairy cows changes during the lactation cycle. J. Dairy Sci. 102:5458-5465. https://doi.org/10.3168/jds.2018-15950.

Varcoe, T. J., K. L. Gatford, A. Voultsios, M. D. Salkeld, M. J. Boden, L. Rattanatray, and D. J. Kennaway. 2014. Rapidly alternating photoperiods disrupt central and peripheral rhythmicity and decrease plasma glucose, but do not affect glucose tolerance or insulin secretion in sheep. Exp. Physiol. 99:1214-1228. https://doi .org/10.1113/expphysiol.2014.080630.

Vasilatos, R., and P. J. Wangsness. 1981. Diurnal variations in plasma insulin and growth hormone associated with two stages of lacta- tion in high producing dairy cows. Endocrinology 108:300-304. https://doi.org/10.1210/endo-108-1-300.

Verwey, M., and S. Amir. 2009. Food-entrainable circadian oscillators in the brain. Eur. J. Neurosci. 30:1650-1657. https://doi.org/10 $.1111 /$ j.1460-9568.2009.06960.x.

Wang, Y., and M. B. Brown. 1996. A flexible model for human circadian rhythms. Biometrics 52:588-596. https://doi.org/10.2307/ 2532897.

Wilson, D. L., A. Fung, S. P. Walker, and M. Barnes. 2013. Subjective reports versus objective measurement of sleep latency and sleep duration in pregnancy. Behav. Sleep Med. 11:207-221. https://doi .org/10.1080/15402002.2012.670674.

Wiltbank, M. C., R. Meidan, J. Ochoa, G. M. Baez, J. O. Giordano, J. C. P. Ferreira, and R. Sartori. 2016. Maintenance or regression of the corpus luteum during multiple decisive periods of bovine pregnancy. Anim. Reprod. 13:217-233. https://doi.org/10.21451/ 1984-3143-AR865.

Yamazaki, S., R. Numano, M. Abe, A. Hida, R. Takahashi, M. Ueda, G. D. Block, Y. Sakaki, M. Menaker, and H. Tei. 2000. Resetting central and peripheral circadian oscillators in transgenic rats. Science 288:682-685. https://doi.org/10.1126/science.288.5466.682.

Zhang, X., J. Dong, and D. Raftery. 2020. Five easy metrics of data quality for LC-MS-based global metabolomics. Anal. Chem. 92:12925-12933. https://doi.org/10.1021/acs.analchem.0c01493.

Zhao, H., Y. Wang, B. Yuan, S. Liu, S. Man, H. Xu, and X. Lu. 2016. A novel LC-MS/MS assay for the simultaneous determination of melatonin and its two major metabolites, 6-hydroxymelatonin and 6-sulfatoxymelatonin in dog plasma: Application to a pharmacokinetic study. J. Pharm. Biomed. Anal. 117:390-397. https://doi .org/10.1016/j.jpba.2015.09.028.

\section{ORCIDS}

Aridany Suarez-Trujillo @ https://orcid.org/0000-0002-9343-5016

Dawn Conklin @ https://orcid.org/0000-0003-0483-4734

Radiah C. Minor $\odot$ https://orcid.org/0000-0002-8948-4819

Jonathan Townsend (ํ) https://orcid.org/0000-0002-9705-0455

Karen Plaut $\odot$ https://orcid.org/0000-0002-3239-9197

Uduak Z. George ๑ https://orcid.org/0000-0003-2208-3671

Jacquelyn Boerman ำ https://orcid.org/0000-0002-0336-8295

Theresa M. Casey (๑) https://orcid.org/0000-0002-8835-3550 